\title{
Los terremotos antiguos del conjunto arqueológico romano de Baelo Claudia (Cádiz, Sur de España): Quince años de investigación arqueosismológica
}

\author{
Ancient earthquakes in the Roman city of Baelo \\ Claudia (Cádiz, South of Spain): Fifteen years of \\ archaeosimology research
}

\author{
P.G. Silva ${ }^{1}$, J.L. Giner-Robles ${ }^{2}$, K. Reicherter ${ }^{3}$, M.A. Rodríguez-Pascua ${ }^{4}$, C. Grützner ${ }^{5}$,

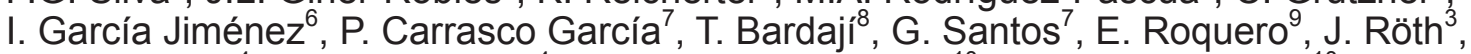 \\ M.A. Perucha ${ }^{4}$, R. Pérez-López ${ }^{4}$, B. Fernández Macarro ${ }^{10}$, A. Martínez-Graña ${ }^{10}$, J.L. Goy ${ }^{10}$, \\ C. Zazo ${ }^{11}$ \\ 1 Dpto. Geología, Escuela Politécnica Superior de Ávila, Universidad de Salamanca. 05003-Ávila. España. Email: pgsilva@usal.es \\ 2 Dpto. Geología y Geoquímica. Fac. Ciencias. Universidad Autónoma de Madrid. Madrid. España. Email: jorge.giner@uam.es \\ 3 Institute of Neotectonics and Natural Hazards, RWTH Aachen University, 52064 Aachen. Alemania. \\ Email: k.reicherterr@nug.rwthaachen.de \\ 4 Área de Riesgos Naturales Instituto Geológico y Minero de España, IGME. Madrid. España. Emails: ma.rodriguez@igme.es, \\ ma.perucha@igme.es \\ 5 Department of Earth Sciences, University of Cambridge, Cambridge, United Kingdom. Email: chg39@cam.ac.uk \\ 6 Conjunto Arqueológico Romano de Baelo Claudia, Junta de Andalucía, Cádiz, España. Email: ivan.garcia@juntadeandalucia.es \\ 7 Dpto. Ing. Del Terreno, Escuela Politécnica Superior de Ávila, Universidad de Salamanca. 05003-Ávila España. \\ Email: retep81@usal.es,gsd@usal.es \\ 8 U.D. Geología, Universidad de Alcalá, 28871 Alcalá de Henares, Madrid, España. Email: teresa.bardaji@uah.es \\ 9 Dpto. Edafología, E.T.S.I Agrónomos. Universidad Politécnica de Madrid. 28040-Madrid, España. Email: elvira.roquero@upm.es \\ ${ }^{10}$ Dpto. Geología Facultad de Ciencias, Universidad de Salamanca.38000-Salamanca, España. Emails: begom@usal.es, \\ joselgoy@usal.es \\ 11 Dpto. Geología, Museo Nacional de Ciencias Naturales (CSIC), 28006-Madrid, España. Email: mcnzc65@mncn.csic.es
}

\section{RESUMEN}

El presente trabajo ilustra el estado del conocimiento sobre arqueosismología en la antigua ciudad romana de Baelo Claudia (Tarifa, Cádiz) tras casi quince años de investigaciones. Esta antigua ciudad romana se vio afectada por dos importantes terremotos en los años 40-60 AD y 260-290 AD. El primero de ellos afectó en mayor grado a la parte baja (costera) de la ciudad provocando importantes cambios urbanísticos y arquitectónicos (monumentalización) en respuesta a las labores de reconstrucción. El segundo de ellos provocó una mayor destrucción, cuya ruina progresiva desembocó en el abandono definitivo de la ciudad en el 365-390 AD. Se catalogan, cartografían y describen la mayor parte de los Efectos Arqueológicos de los Terremotos (EAEs) del sector monumental de la ciudad, que testifican los efectos producidos por el terremoto ocurrido en el 260-90 AD. La cartografía de daños (EAEs) muestra la distribución y orientación de los daños en la zona baja de la ciudad, así como la ocurrencia de otros procesos cosísmicos, como deslizamientos y pequeños tsunamis. El análisis estructural del conjunto de daños orientados indica que la dirección de movimiento del terreno se produjo en una dirección dominante del SO al NE.

Recibido el 7 de octubre de 2015 / Aceptado el 18 de marzo de 2016 / Publicado online el 23 de junio de 2016

Citation / Cómo citar este artículo: Silva, P.G. et al. (2016). Los terremotos antiguos del conjunto arqueológico romano de Baelo Claudia (Cádiz, Sur de España): Quince años de investigación arqueosismológica. Estudios Geológicos 72(1): e050. http://dx.doi. org/10.3989/egeol.42284.392.

Copyright: () 2016 CSIC. This is an open-access article distributed under the terms of the Creative Commons Attribution-Non Commercial (by-nc) Spain 3.0 License. 
Los análisis geoarqueológicos, así como importantes anomalías constructivas y funerarias, sugieren la intervención de tsunamis de escaso poder de penetración durante los dos terremotos, apuntando a la existencia de una fuente sísmica submarina común al SSO de la ciudad. Se han identificado diferentes fallas normales de dirección N-S en la zona de la Bahía de Bolonia, algunas de las cuales se prolongan hacia el interior del mar en la zona SSO de Baelo Claudia. Estas fallas presentan claras evidencias de actividad Cuaternaria y podrían considerarse como las fuentes sísmicas más probables para los dos antiguos terremotos que afectaron a la ciudad en época romana.

Palabras clave: Arqueosismología; Efectos Arqueológicos de los Terremotos (EAEs); Baelo Claudia; Estrecho de Gibraltar; Sur de España.

\section{ABSTRACT}

This work illustrates the state of the art on archaeoseismology of the ancient Roman city of Baelo Claudia (Tarifa, Cádiz) after nearly fifteen years of research. This ancient Roman site was affected by two earthquakes in the years AD 40-60 and AD 260-290 which promoted important urban and architectural changes and eventually the destruction and further abandonment of the city in AD 365-390. Earthquake Archaeoseismological Effects (EAEs) are catalogued, described and mapped in the entire monumental sector of the city mainly witnessing the last earthquake which occurred in AD 260-290. Mapping of oriented EAEs illustrate damage distribution all over the lower sector of the city, as well as the occurrence of suspect coseismic landslide and tsunami events. The structural analysis of oriented EAEs throughout the entire mapped sector suggests that the intervening ground motion was preferentially oriented in a SW to NE direction. The geoarchaeological analysis and some relevant archaeological anomalies, strongly suggest the occurrence of coeval tsunami events during both ancient earthquakes, pointing to the occurrence of an offshore seismic source SSW of the city. Several N-S normal faults have been identified around the Bolonia Bay area and some of them continue offshore SSW of Baelo Claudia. These faults with clear Quaternary activity can be considered as the more probable seismic sources for the events affecting the ancient Roman site and they are consistent with the mapped damage orientation displayed by the structural analysis of EAEs within the old Roman city. Spain.

Keywords: Archeoseismology; Earthquake Archaeological Effects (EAEs); Baelo Claudia; Gibraltar Strait; South

\section{Introducción}

La ciudad romana de Baelo Claudia fue fundada en el siglo II AC como un lugar estratégico para el tránsito de personas y mercaderías entre Europa y el norte de África (Sillières, 1997). El Geógrafo Griego Estrabón (Siglo II DC) describió este asentamiento (Belon) como un importante centro industrial pesquero y de "garum", así como el principal puerto para alcanzar Mauritania Tingitana al otro lado del Estrecho de Gibraltar (Fig. 1). Las excavaciones arqueológicas en la ciudad ponen de manifiesto tres periodos bien diferenciados, los cuales están separados por importantes discontinuidades en el registro arqueológico. Desde inicios de los años ochenta estas discontinuidades arqueológicas fueron ligadas a la ocurrencia de eventos sísmicos (Meanteau et al., 1983; Sillières, 1997). Estudios posteriores (Silva et al., 2005; 2009; Grützner et al., 2012) claramente indican a la ocurrencia de dos terremotos (40-60 AD y 260-290 AD) como los sucesos más decisivos en la historia del urbanismo de esta antigua ciudad romana (Silva y Rodríguez-Pascua, 2014).

El antiguo asentamiento, fundado en el siglo II $\mathrm{AC}$, es sustituido por una autentica ciudad romana durante la primera mitad del siglo I DC, cuando adquirió el rango de Oppidum Latinum entre los años 41 y 48 AD (Sillières, 1997). Así desde la segunda mitad del siglo I DC la ciudad experimentó un importante crecimiento urbanístico, adquiriendo un carácter monumental con la construcción de importantes edificaciones públicas, como Foro, Basílica, Termas, etc. (Sillières, 1997). La Figura 2 muestra una reconstrucción paleogeográfica de Baelo Claudia tras su reconstrucción en la segunda mitad del siglo I DC, en la que el único elemento no existente sería el extenso coluvión post-romano que enterraba la ciudad antes de su excavación (Silva et al., 2009). Los datos arqueológicos indican que la mayoría de edificios públicos comenzaron a construirse en el 40-50 AD y su construcción estaba completamente finalizada en el 70-80 AD, fechas entre las que se sitúa el primer evento sísmico que afectó a la ciudad (Silva et al., 2005).

El primer periodo de destrucción de la ciudad se encuentra datado entre los años 40-60 AD. El análisis geoarqueológico de los sondeos geotécnicos realizados en la ciudad indican que ese primer periodo de destrucción puede ligarse a un evento sísmico que afectó gravemente a la parte baja de la 


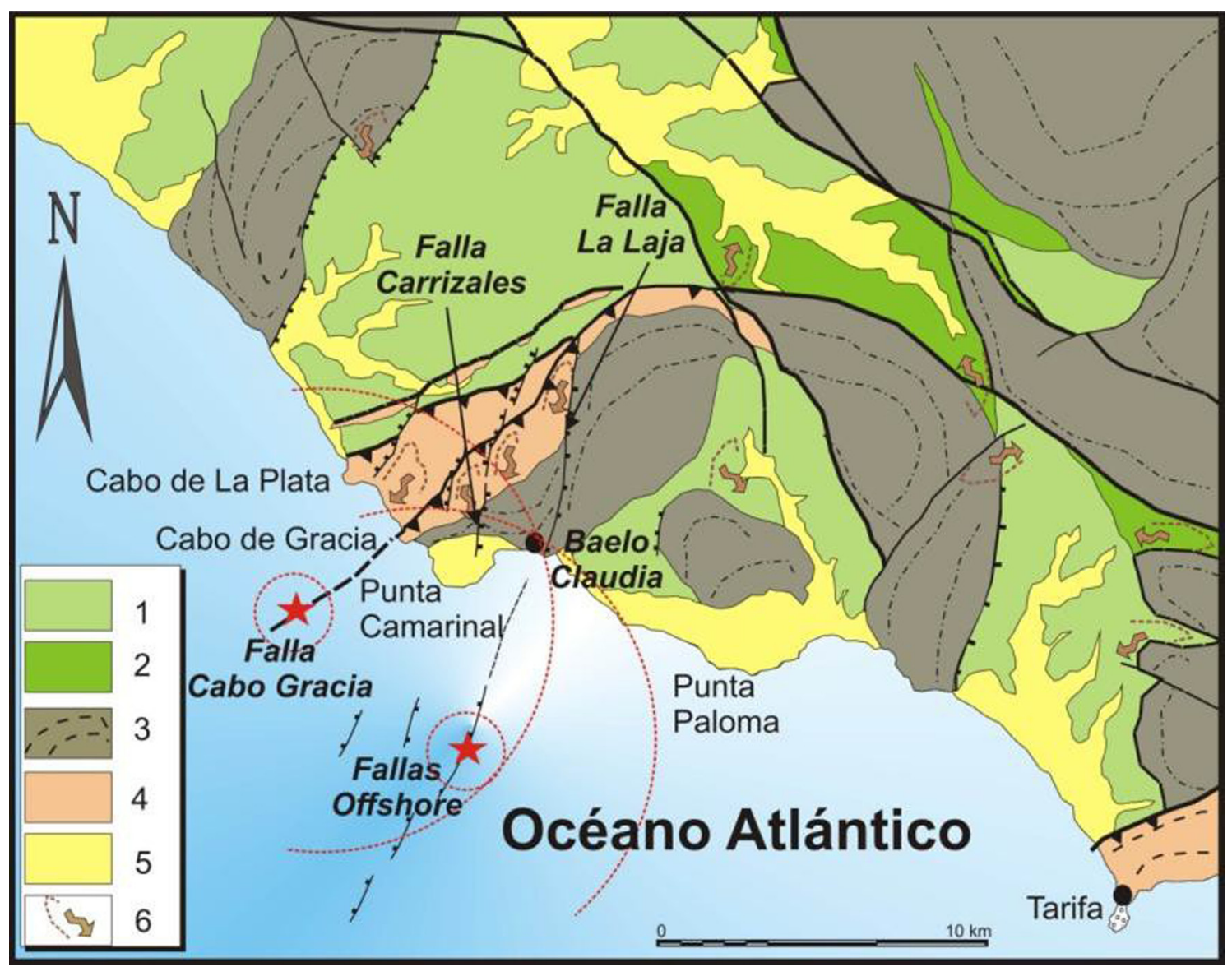

Fig. 1.-Contexto Geológico de la Bahía de Bolonia en el que se representan los sistemas de fallas más importantes de la zona central del Estrecho de Gibraltar y las fuentes sísmicas más probables en la zona identificadas con estrellas rojas. Estas muestran las posiciones hipotéticas de posibles epicentros congruentes con las orientaciones de daños registradas en el Conjunto Arqueológico Romano de Baelo Claudia para el siglo IV d. C. Leyenda: 1) Fm. Almarchal; 2) Fm. Facinas; 3) Fm. Superior de las areniscas del Aljibe (Fm. Bolonia) en la que las direcciones de estratificación y pliegues subverticales se identifican con líneas a trazos; 4) Fm. Inferior de las areniscas del Aljibe y Fm. Algeciras; 5) materiales post-orogénicos del Mioceno superior, Plioceno y Cuaternario; 6) Grandes deslizamientos identificados en la zona. Las fallas normales (con cuadrados) e inversas (con triángulos) se identifican mediante la simbología convencional. También se ha incluido una síntesis de las fallas presentes en la plataforma identificadas por Grützner et al. (2012).

ciudad (Silva et al., 2005) y al conjunto de su recinto amurallado que quedó destruido en sus dos terceras partes (Sillières, 1997). Silva et al. (2005) identifican un horizonte de demolición romano, sobre el cual se reedifica y expande la antigua ciudad romana. Los trabajos de reconstrucción de la ciudad y renivelación del terreno afectaron a no menos de $500 \mathrm{~m}^{2}$ de la zona baja del recinto urbano. Muchos de los antiguos elementos estructurales y decorativos fueron reutilizados para la reconstrucción de la ciudad y las murallas reparadas, reforzadas y recrecidas (Sillières, 1997). Excavaciones arqueológicas recientes han puesto claramente a la luz la superposición de elementos urbanísticos anteriores y posteriores al evento que afectó a la antigua ciudad romana.
El caso, es que bajo el mandato de Claudio, la ciudad adquirió el rango de ciudad romana y el apellido de Claudia. La estatua del Emperador fue encontrada entre las ruinas de la Basílica.

A partir de la segunda mitad del siglo I y hasta finales del siglo III DC la ciudad experimentó un auge en actividad comercial y prosperidad. No obstante, en torno a los años 260-290 AD la antigua ciudad romana sufre un nuevo periodo de destrucción que diferentes autores (Sillières, 1997; Silva et al., 2005; 2009; Grützner et al., 2012) atribuyen a un fuerte terremoto de intensidad $\leq$ VIII EMS que afectó a todo el conjunto amurallado y zona monumental de la ciudad. Las deformaciones generadas en monumentos y edificaciones por este segundo 




Fig. 2.-Mapa paleo-geomorfológico de la Bahía de Bolonia durante el siglo I a.C. basado en cartografía geomorfología (Silva et al., 2005) y datos arqueológicos submarinos y perfiles geofísicos aportados en el trabajo de Alonso-Villalobos et al. (2003). También se ilustra la localización de los sondeos geotécnicos (S) más representativos realizados en la zona por Vorsevi S.A. (Borja et al., 2003; Silva et al., 2005) y los sondeos de prospección realizados por Alonso-Villalobos et al. (2003). Leyenda: 1) plataforma de abrasión marina; 2) Terrazas marinas del Pleistoceno Superior; 3) Sustrato Bético; 4) Spit-bars holocenos incluyendo los sistemas dunares D1 y D2 de la zona atlántica; 5) Antiguos spit-bars de época romana, actualmente desaparecidos; 6) zonas de marisma; 7) Coluvión post-romano; 8) llanuras aluviales de los sistemas de arroyos de la zona; 9) Canales activos y distributarios; 10) Canales distributarios abandonados (no-funcionales) en la actualidad; 11) Edificaciones y restos arqueológicos romanos; 12) Estructuras portuarias romanas; 13) Acumulaciones de bloques y sillares bajo el nivel del mar; 14) Paleoacantilado; 15) Escarpes rocosos por erosión diferencial. Los edificios romanos más importantes que se identifican en la figura son: Teatro (Th); Templos (Tp); Foro (F); Basílica (B); Macellum (M); Fabricas de salazón (Ff); y Termas (Tr).

evento son las que se pueden observar en la actualidad y el objetivo principal de este trabajo.

\section{Los Terremotos de Época Romana en Baelo Claudia}

En la actualidad las ruinas de la antigua ciudad romana muestra claras señales de la causa de su deterioro en la segunda mitad del siglo III
DC (evento sísmico) y de su posterior abandono a finales del siglo IV DC (estado de ruina). El declive del Imperio Romano por esas fechas no permitió la reconstrucción de la ciudad, como ocurrió en su época de esplendor a partir de mediados del siglo I AD. En un principio, Menanteau et al. (1983) y Silva et al. (2005) atribuyen el segundo evento sísmico al periodo 365-395 $\mathrm{AD}$, aunque posteriormente lo sitúan en el 260-290 AD (Silva et al., 2009). 
En un principio estos autores ligan el declive y abandono definitivo de la ciudad a terremotos ocurridos entre los años 365 AD (Mediterráneo) y 390 AD (Atlántico). En concreto, estas interpretaciones se apoyaban en las descripciones del catálogo sísmico de Galbis (1932), basadas en la trascripción de los textos del historiador romano Amiano Marcelino (330-378 AD).

"En el año segundo del reinado de Valentiniano y Valente (21/07/365), al rayar el alba de dicho día, se sintió en las provincias granadinas y en otras del imperio un violento terremoto. Las olas del Mediterráneo hirvieron como en la más deshecha borrasca. A muchas varas de distancia de Málaga y Adra, quedaron en seco las playas, que siempre habian estado bañadas por las aguas: los pescados, faltos de su natural elemento, eran cogidos a mano sobre la arena sin redes ni anzuelo. Absortos los habitantes de la costa, vieron la profundidad de los abismos, que colmatados de agua estaban quizás desde el principio del mundo. Al cabo de algunas horas retrocedió la mar con ímpetu furioso; los buques, que habian encallado en la arena, fueron lanzados con irresistible empuje dentro de tierra, y estrellados algunos contra los edificios de las ciudades cercanas. Las aguas inundaron los pueblos de la ribera, ahogando a multitud de familias".

El catálogo de terremotos históricos en la Península Ibérica (Martínez Solares y Mezcua, 2002) no incluyen este evento, ya que otros estudios (Udías y Muñoz, 1983) indican que este terremoto se correspondería con el gran terremoto-tsunami de Creta (Mar Egeo) ocurrido en el 365 AD. No obstante obras posteriores (Espinar Moreno, 1994) siguen considerando este evento indicando que Galbis (1932) lo sitúa como ocurrido en la costa de Málaga, con intensidad IX MSK y magnitud 6,3 Ms. No obstante, salvo la descripción realizada en el tercer tomo de la obra "historias" de Amiano Marcelino, no existe ningún otro dato que apoye la ocurrencia de tal terremoto en el Mediterráneo occidental. Por el contrario, del gran terremoto-tsunami de Creta se tiene amplia constancia documental y arqueológica en el Mediterráneo oriental. Algunos autores (e.g. Stiros, 2001) indican que los datos actuales no permiten interpretar que este evento tuviera efectos relevantes más allá del Estrecho de Sicilia (Sur de Italia), sugiriendo que las destrucciones atribuidas al evento de
Creta en las costas del Mediterráneo occidental pueden estar sencillamente relacionadas con la multitud de "terremotos locales" que tuvieron lugar a lo largo de todo el Mediterráneo entre los siglos IV y VI DC durante la denominada "Crisis Tectónica Bizantina Temprana" (Early Bizantine Tectonic Paroxysm). Apoyados en estos datos, Silva et al. (2005) indican que el terremoto que afectó a Baelo Claudia pudo ser un evento local ocurrido en la zona marina adyacente a la Bahía de Bolonia.

De ser así, un terremoto-tsunami local no provocaría la destrucción total de Baelo Claudia, pero incluso un pequeño tsunami de 1-2 $\mathrm{m}$ de altura que azotara la Bahía de Bolonia pudo suponer la puntilla que acabara por destruir y arruinar las pocas maltrechas edificaciones que quedaran en la ciudad después del 290 AD teniendo en cuenta la paleogeografía de la zona (Fig. 2). De hecho tanto en la Bahía de Bolonia (Alonso-Villalobos et al., 2003) como en la antigua ciudad romana de Carteia en la Bahía de Algeciras (Arteaga y González Martín, 2004) se registran niveles energéticos litorales de época romana, cuyas edades estimadas podrían corresponder a cualquiera de los eventos aquí relacionados de los siglos I, III o IV DC (Lario et al., 2010). Más recientemente (Röth et al., 2015) identifican depósitos de tsunamitas con microfauna marina en el interior de la propia Baelo Claudia (Decumanus maximus y Termas Marítimas). Las edades $\mathrm{C}^{14}$ aportadas por estos autores son consistentes con el terremoto ocurrido en el 260-290 AD o bien con el propio abandono definitivo de la ciudad en el 360-395 AD. Estos depósitos, de hasta un máximo de $60 \mathrm{~cm}$ de potencia, indican un tsunami de escaso poder de penetración tierra adentro (c. $200 \mathrm{~m}$ ) y run-up máximo de $8 \mathrm{~m}$ (Röth et al., 2015).

En cualquier caso, los estudios realizados en la zona y el hecho de que de estos terremotos no se tenga mención histórica expresa de que afectara a Baelo Claudia o a cualquier otra ciudad próxima, podría indicar que los eventos de los siglos I y III DC fueron causados por fuentes sísmicas locales situadas en campo cercano. Estas podrían corresponder con la prolongación offshore de fallas próximas como la de Cabo de Gracia, Cantera Carrizales o La Laja (Silva et al., 2005; 2009). Estudios de sísmica de reflexión realizados offshore han localizado fallas de dirección aproximada N-S afectando a los depósitos cuaternarios y suelo marino de la 
misma en la parte central y oriental de la Bahía de Bolonia (Grützner et al., 2012). Estos autores proponen estas fallas, localizadas hasta una distancia de $20 \mathrm{~km}$ offshore, como las fuentes sísmicas más probables que generaron estos eventos (Fig. 1). Por otro lado, las estimaciones realizadas en la zona urbana de Baelo Claudia en base a datos geotécnicos existentes (Borja et al., 1993) indican un más que posible efecto sitio (amplificación sísmica), pudiéndose alcanzar en la zona aceleraciones sísmicas entorno a los $0,33 \mathrm{~g}$ según la NCSE-02, por la ocurrencia de un terremoto cercano y superficial (Silva et al., 2009). La parametrización del mismo, según las dimensiones de las probables fuentes sísmicas y los daños registrados, indicaría unas magnitudes mínimas de 5,5-6,0 Mw e intensidades mínimas de VIII - IX EMS.

En definitiva, el problema de los terremotos de Baelo Claudia es que no se encuentran documentados históricamente, pero esto es un hecho que alcanza casi en igual medida a la propia ciudad, tan solo mencionada brevemente por Estrabón. Así las cosas, no existe ningún dato documental histórico sobre la historia de la ciudad, la cual ha sido "progresivamente construida" (como otras muchas) en base a los datos arqueológicos (Sillières, 1997). Ningún dato indica la ocurrencia de guerras, asaltos, etc, en la ciudad, ni tampoco explican las numerosas anomalías arqueológicas y multitud de daños orientados y evidencias geológicas, que apoyan los dos "terremotos perdidos" que han salido a la luz a través del estudio arqueosismólogico del Conjunto Arqueológico Romano de Baelo Claudia.

\section{Los efectos Arqueológicos de los Terremotos (EAEs)}

Los efectos arqueológicos de terremotos (Earthquake Archaeological Effects, EAEs) son todos aquellos efectos asociados a la ocurrencia de un sismo y que se pueden analizar a partir del registro arqueológico y geológico dentro del contexto de un yacimiento arqueológico (Rodríguez Pascua et al., 2011). El principal interés en la caracterización de estos efectos es documentar y caracterizar daños producidos por terremotos destructivos en el intervalo histórico definido por el yacimiento arqueológico.
Numerosos trabajos han puesto de manifiesto diferentes daños asimilables a la ocurrencia de terremotos en diversos contextos arqueológicos y periodos históricos (Stiros y Jones, 1996; 2000; Ambraseys, 2006; Marco, 2008). Rodríguez-Pascua et al. (2011) desarrollaron una clasificación de los diferentes EAEs que pueden aparecer en el contexto de un yacimiento arqueológico, definiendo una estructura de análisis para su aplicación en cualquier yacimiento arqueológico perteneciente a cualquier periodo histórico y cultura que levantase edificaciones (Fig. 3). La caracterización de terremotos desconocidos, o poco documentados en el registro histórico, son una importante fuente de información sísmica que puede ser incorporada a los catálogos sísmicos convencionales para el estudio de la peligrosidad sísmica. Los yacimientos arqueológicos pueden utilizarse como antiguos sismógrafos ("seismoscopios") que potencialmente pueden registrar lo que científicamente se denominan "terremotos antiguos" (Sintubin et al., 2010), esto es "terremotos perdidos" tan solo documentados por datos arqueológicos. En España existen diversos ejemplos de análisis arqueosismológicos, los más recientemente documentados en Complutum (Alcalá de Henares; Rodríguez-Pascua et al., 2014; 2016), y en el yacimiento del Bronce de La Tira del Lienzo (Totana; Ferrater et al., 2015).

El inventario y análisis de EAEs permite establecer las direcciones de máxima deformación que los han producido (Giner-Robles et al., 2009) esto es, la dirección preferente de movimiento del terreno causado por la propagación de las ondas sísmicas superficiales responsables de lo que se denomina "sacudida sísmica". Si estas deformaciones están producidas por diferentes procesos (destrucción bélica, demoliciones, etc.), o por procesos de carácter muy local (deslizamientos, colapsos del terreno, etc.), no presentarían orientaciones necesariamente homogéneas. Por el contrario, la homogeneidad en la orientación de daños (EAEs), junto con la eliminación de otros procesos que puedan producir esas deformaciones homogéneas en todo el yacimiento, permite establecer su posible origen sísmico. Existen diferentes tipos de EAEs, y tal y como muestra la figura 3, unos indican la dirección de la máxima deformación del terreno, mientras que otros indican su dirección y sentido (Giner-Robles et al., 2011; Rodríguez-Pascua et al., 2011). Muchos de estos 


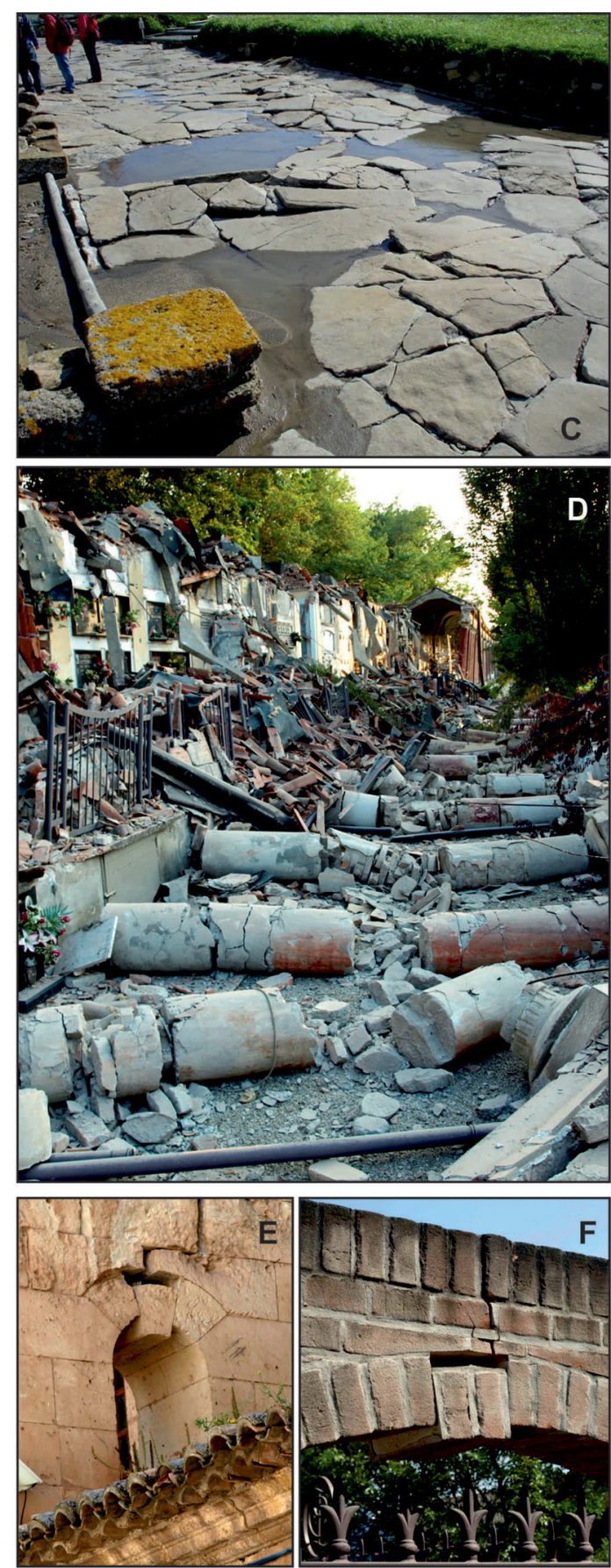

Fig. 3.-Tabla de clasificación de los Efectos Arqueológicos de Terremotos (EAEs: Earthquake Archaeological Effects), modificado de Rodríguez-Pascua et al., 2009 y 2011: A) efectos cosísmicos, efectos producidos directamente por el evento sísmico (geológicos y en la fábrica de las construcciones); B) efectos post sísmicos, efectos indirectos producidos por las consecuencias del terremoto, ya sean visibles en el registro geoarqueológico (efectos de registro), o en las construcciones posteriores al evento sísmico (efectos constructivos). C) En la ciudad de Baelo Claudia se han utilizado principalmente los efectos en las fábricas de las construcciones presentes en el yacimiento, como los pliegues (anticlinales y sinclinales) en el enlosado irregular del Decumanus Maximus de Baelo, consecuencia del terremoto que afectó a la ciudad en 260 - 290 AD; D) Caída orientada de la columnata del muro sur (E-O) del cementerio de Mirandola (Italia) como consecuencia del terremoto 5,9 Mw de la Emilia Romagna del 28 de mayo de 2012; E) Caída de claves en los arcos de sillería de la colegiata de San Patricio Lorca consecuencia del terremoto 5,1 Mw del 11 de mayo de 2011 ; y F) en los arcos de ladrillo en una casa de Finale Emilia (Italia) causados por el terremoto del 20 de mayo de 2012 en Emilia Romagna. 


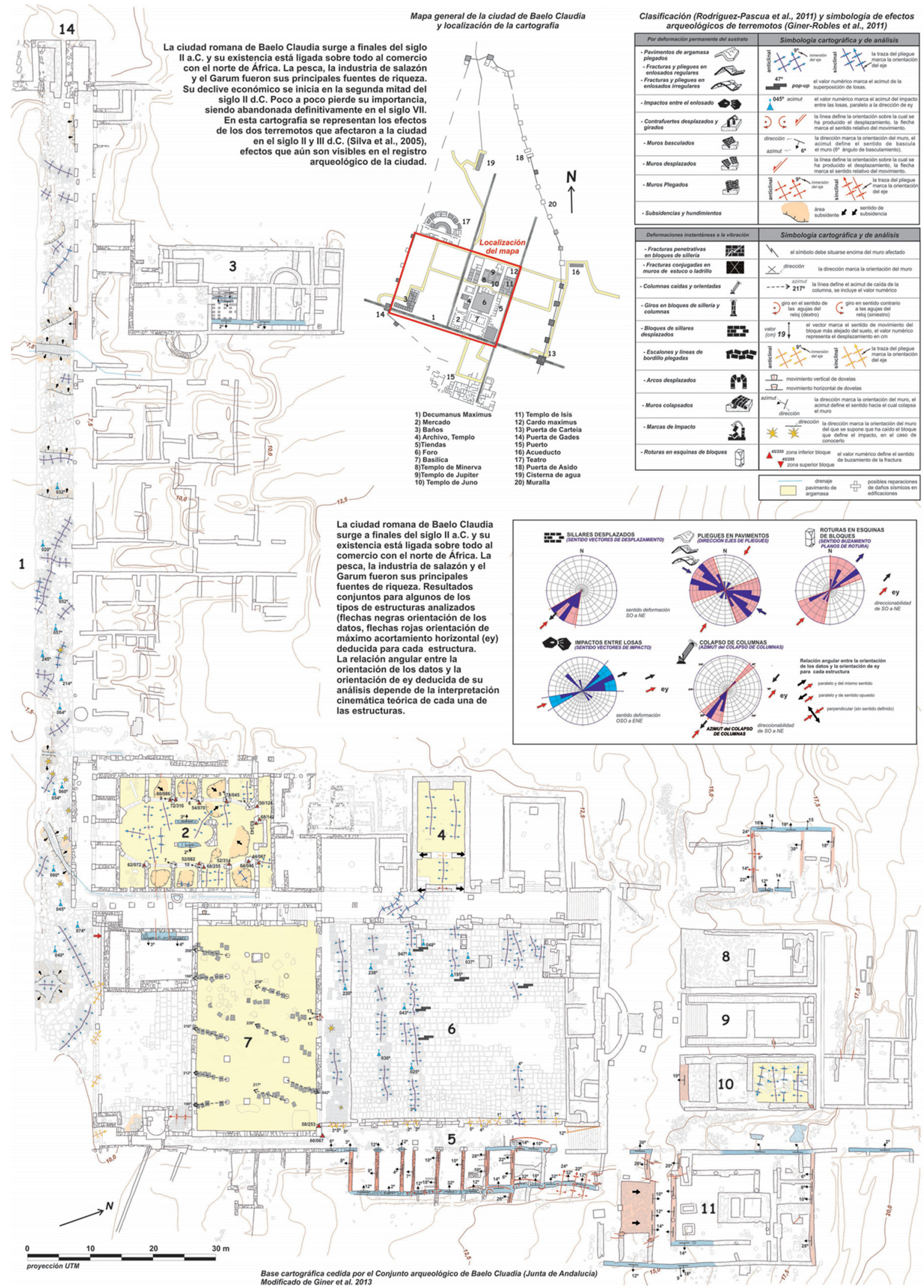


efectos se han inventariado y chequeado durante el análisis de daños producidos por terremotos recientes como el de Lorca de 2011 (5.1 Mw) y el de Emilia-Romagna 2012 (5.9 Mw) de tamaño similar al que podrían generar las fuentes sísmicas cercanas más probables situadas alrededor de la Bahía de Bolonia (Fig. 1).

Es evidente que los estudios arqueosismológicos de este tipo deben estar apoyados y corroborados por datos procedentes de otras disciplinas científicas: arqueología, geomorfología, geología estructural, geofísica e historia (en el caso de que exista documentación histórica relacionada). No obstante, es importante insistir en que hay que realizar un análisis exhaustivo de las deformaciones del terreno registradas por los EAEs para poder interpretarlas adecuadamente. La figura 4 muestra la cartografía de daños que se ha realizado para el yacimiento de Baelo Claudia (Giner-Robles et al., 2013) en el que se puede observar el inventario actualizado y cartografía de EAEs.

La figura 4 también muestra el análisis de orientación de daños realizado para el conjunto del yacimiento arqueológico en la que claramente se puede observar que los daños analizados muestran una clara direccionalidad SO - NE. Si consideramos los resultados obtenidos de forma conjunta para todo el yacimiento, se puede definir una dirección de deformación horizontal máxima del terreno según N35$\mathrm{N} 40^{\circ} \mathrm{E}$, indicando que las ondas sísmicas procedían del cuadrante SO de la Bahía de Bolonia (Fig. 2), donde por otra parte se encuentran las fuentes sísmicas más probables identificadas por distintos autores (Goy et al., 1995; Silva et al., 2005; 2009; Grützner et al., 2012). Así pues la orientación de daños homogénea obtenida a partir del análisis arqueosismológico de EAEs (Giner-Robles et al., 2011) corrobora, arqueométricamente (de forma cuantitativa), el origen sísmico de las deformaciones correspondientes al evento que afectó a la ciudad romana en la segunda mitad del siglo III DC (Sillières, 1997; Silva et al., 2009). Por el contrario, el terremoto que afectó a la ciudad romana en el siglo I DC se encuentra escasamente documentado como para realizar un análisis de EAEs similar. No obstante, La destrucción del lienzo oriental de la muralla (Silva et al., 2009), colapsos orientados en el Templo de Isis (Grützner et al., 2012), la presencia de un horizonte de demolición para la reconstrucción de la ciudad (Silva et al., 2005), algunas anomalías arqueológicas relevantes relacionadas con el Teatro (Finker y Sillières, 2006), y en el segundo nivel de enterramientos de la necrópolis oriental de la ciudad (Prados Martínez, 2011), apoyan la ocurrencia del evento sísmico (Silva y Giner-Robles, 2014). Las excavaciones recientes al Este de la Basílica permiten observar hoy día las claras relaciones de corte entre las estructuras deformadas de la primera ciudad (siglo I DC) y la segunda (siglo III DC) y el horizonte de demolición que se localiza entre ambas (Fig. 5), que con anterioridad solo se había testificado en sondeos mecánicos y pequeñas catas arqueológicas (Silva et al., 2005).

\section{EI Registro Arqueosísmico de Baelo Claudia}

Como se ha comentado anteriormente, la mayor parte de los efectos arqueológicos de los terremotos (EAEs) presentes en el yacimiento corresponden al terremoto que provocó la destrucción de la ciudad y su progresivo abandono, fechado en el 260-290 AD (Silva et al., 200), siguiendo la cronología del yacimiento propuesta por Sillières (1997). Los EAEs más representativos se concentran en las siguientes zonas: a) Muralla y Acueducto; b) Templo de Isis; c) Foro y Basílica; d) Mercado; e) Decumanus maximus; f) Teatro y; g) Necrópolis oriental. De todas ellas, tan solo el Teatro y la Necrópolis oriental no

\footnotetext{
Fig. 4. - (Continued) Cartografía de EAEs registrados en el Conjunto Arqueológico de Baelo Claudia (Giner-Robles et al., 2013), donde se muestra la distribución de daños relacionados con el terremoto del 260-280 AD y el análisis estructural geológico de la orientación de los daños registrados en el yacimiento, a partir del cual se puede deducir la dirección y sentido de la deformación del terreno que los ha producido. La homogeneidad de los resultados (ey) permite inferir el origen sísmico de las deformaciones. En algunos casos es posible incluso establecer la posición relativa del epicentro del terremoto (Giner-Robles et al., 2011). En los diagramas de direcciones se pueden observar los resultados para algunas de las estructuras analizadas (EAEs) en el yacimiento, así como el resultado del análisis de la deformación para el conjunto del yacimiento. En estos diagramas, las flechas azules marcan la orientación de la máxima deformación (ey) deducida para cada EAE. La relación angular entre la orientación de los datos y la orientación de ey deducida de su análisis depende de la interpretación cinemática teórica de cada una de las estructuras (Giner-Robles et al., 2011). Base cartográfica del mapa general y de los mapas de detalle que se muestran en siguientes figuras, cedida por el Conjunto Arqueológico de Baelo Claudia, Junta de Andalucía.
} 



Fig. 5.-Relaciones espaciales entre estructuras murarías de la primera fase de la ciudad ( $\leq$ Siglo I), segunda fase (Siglo I - Siglo IV) y el horizonte de demolición de la segunda mitad del siglo I. A) Relaciones de corte de estructuras murarías al Este de la plaza de la Basílica. B) Vista de las mismas estructuras desde el Sur, en la que se observa el horizonte de demolición intermedio. Obsérvese el importante reciclaje de sillares, tambores de columnas, etc., que aparecen en la reconstrucción de la ciudad sobre el horizonte de demolición. C) Vista general del horizonte de demolición estructuras amortizadas del siglo I bajo la zona de la Basílica (columnas al fondo). D) Vista de detalle del horizonte de demolición ilustrando las características de los rellenos antrópicos en una antigua puerta de acceso a una vivienda.

aparecen representadas en el mapa de daños de la Fig. 3. A continuación se exponen los datos más relevantes para estos distintos sectores.

\section{Muralla de la ciudad y Acueducto}

La Muralla de la ciudad posee dos fases distintas de construcción, la primera de época Augustea con grandes sillares calizos en seco y la segunda que data de mediados del siglo I DC adosada a la anterior y construida con opus caementicium (Sillières, 1997). La primera muralla de grandes sillares fue destruida casi en sus tres cuartas partes como consecuencia del evento del 40-60 AD, y luego fue reparada y ampliada en muchos puntos reforzando los tramos menos afectados, pero en la mayoría de su perímetro fue reconstruida en su totalidad, utilizando opus caementicium (Sillières, 1997). Este autor fecha las reparaciones y reconstrucción de la antigua muralla entre los años 50 y $60 \mathrm{DC}$, indicando que la muralla de época Agustea quedó en estado de ruina y en la medida de lo posible se intentó conservar o reparar las zonas menos afectadas (una tercera parte de la misma). En cualquier caso los tramos conservados de la primera muralla, en el norte (Bastión Norte) y algunos lienzos de su perímetro oriental, se encuentran visiblemente deformados $\mathrm{y}$ en muchas ocasiones fuertemente basculados (entre 15 y $25^{\circ}$ ) hacia el OSO (Fig. 6) y rectificados por la segunda muralla de opus caementicium que también se encuentra basculada en el mismo sentido en varios sectores (Silva et al., 2009). Las excavaciones en el entorno de la muralla revelan la existencia de numerosos estratos o niveles de colapso de la misma que datan de esta época. También es relevante el hecho que en muchas de las excavaciones realizadas, los sillares colapsados (hasta en número de cinco) se disponen en dominó y direccionalmente hacia el OSO u O (Silva et al., 2009).

Otro tipo de EAEs se encuentra relacionado con las reparaciones. En este sentido se observa como algunas de las grietas (fracturas penetrativas) generadas por el terremoto fueron reparadas (rellenadas) con opus caementicium tras el mismo (Menanteau, 1983). De la misma forma en la zona del Bastión Norte de la muralla se puede observar la puerta de una de las torres de vigilancia de la muralla que 

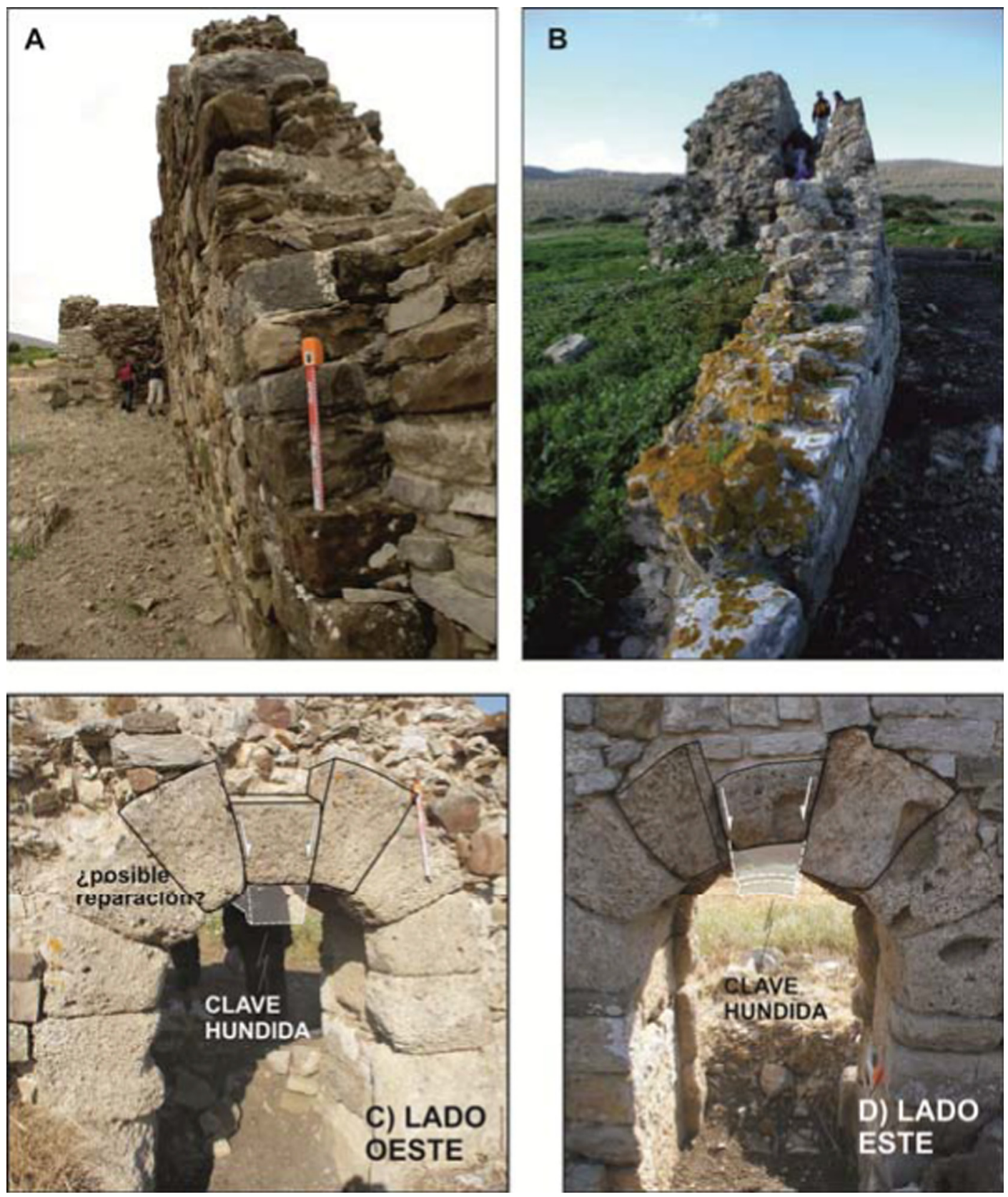

Fig. 6.-Aspecto de los basculamientos y desplazamientos de la muralla de la ciudad provocadas por el tenemoto del 40-60 AD. A) Muralla este de la ciudad en la zona del Bastión Norte; B) Basculamiento de la Muralla oeste de la ciudad en la zona baja del Teatro; Cy D Estructura de reparación de daños producidos el tetTemoto del 40-60 AD en una zona de la muralla oeste de la ciudad (efecto post sísmico constructivo) como consecuencia del hundimiento de la clave central del arco en la puerta de uno de los bastiones de la zona este de la muralla. Las fotos muestran la estructura de reparación vista desde el interior de la ciudad desde el extet·ior de la misma.

presenta una estructura de reparación por el hundimiento de la clave del arco de la puerta tal y como se ilustra en la figura 5 (Giner-Robles et al., 2011).

Las deformaciones en la muralla, muestran como también éstas afectan a los tramos entera o parcialmente reparados durante la segunda mitad del siglo
I DC, los cuales muestran numerosas fracturas verticales penetrativas con desplazamientos decimétricos $(15-12 \mathrm{~cm})$ consecuencia de un proceso de basculamiento diferencial de la misma. En la próxima a la Puerta de Carteia (Este), la muralla presenta diferentes procesos de basculamiento diferencial y colapso que afectan 
tanto a los sillares del siglo I AC que se conservan en su parte basal, como a los tramos superiores construidos con opus caementicium correspondientes a su refuerzo y ampliación a mediados del siglo I DC. En su mayoría los basculamientos se orientan hacia el Oeste, aunque existen algunos sectores donde se encuentran basculados hacia el Este como consecuencia de procesos de derrumbe posteriores, algunos datados en el siglo IV DC. De esta forma todas estas deformaciones, las más visibles en la actualidad, son consecuencia del terremoto del 260-290 AD y su posterior proceso de ruina. Las orientaciones de basculamiento y colapso en este sector de la muralla son congruentes con las correspondientes a las ocasionadas en el 40-60 AD, por lo que permite suponer una fuente sísmica común para ambos eventos (Silva y Giner-Robles, 2014).

Aunque la zona Oeste de la muralla, esté menos excavada y peor conservada, son evidentes los mismos daños que se observan en el lienzo oriental, sobre todo en las proximidades del teatro, donde se observan importantes basculamientos hacia el Oeste, fracturaciones y desplazamientos centimétricos asociados (Fig. 7).

El acueducto oriental de la ciudad, situado extramuros, cruza un pequeño arroyo orientado aproximadamente N-S. Su parte oriental aparece colapsada en el sentido de la pendiente, mientras que la occidental adyacente a la muralla, se encuentra desplazada formando siete fragmentos bien diferenciados (Fig. 7). Algunos de los arcos muestran un desplazamiento rotacional según un eje horizontal, hecho que puede ser interpretado como una deformación lenta originada probablemente por una serie de pequeños desplazamientos paralelos, posiblemente asociados a la reactivación de deslizamientos cosísmicos en esa área (Silva et al., 2009).

\section{El Templo de Isis}

Silva et al. (2009) indican que la mayor parte del daño estructural y arquitectónico que se observa en esta zona es el resultado de un efecto geológico secundario: un deslizamiento con la cabecera en la zona NE del Templo de Isis. El Templo de Isis, junto con los templos de la triada capitolina, se encuentra en una plataforma elevada al Norte del Foro. La mencionada plataforma constituye un aterrazamiento artificial excavado al pié de un paleoacantilado que también fue retocado para la construcción de los templos (Fig. 2). En conjunto toda la zona de los templos representa un talud artificial realizado durante los trabajos de re-edificación de la ciudad a mediados del siglo I DC y relacionado con el horizonte de demolición de escasa calidad geotécnica (Silva et al., 2005; 2009). El Templo de Isis, localizado en el sector más oriental de este talud artificial romano, muestra claros procesos de basculamiento a contrapendiente (hacia el Norte) y desplazamientos decimétricos asociados en sus muros orientados E-O (Fig. 7), indicando que un importante proceso de deslizamiento (hacia el Sur) estuvo involucrado en su destrucción (Silva et al., 2009). No obstante existen grandes lienzos de muro colapsados hacia el Oeste (Figs. 7 y 8 ) que son resultado de un proceso posterior de ruina como indican tanto los elementos arqueológicos que sepulta como las diferentes dataciones $\mathrm{C}^{14}$, que nos sitúan en el siglo IV DC (Grützner et al., 2012).

Estimaciones realizadas por estos autores en base a datos de prospección geofísica de esta zona (georadar) indican que el deslizamiento abarcó un área cercana a los $1000 \mathrm{~m}^{2}$, alcanzando también a la zona del Foro y la galería de tiendas. Prospecciones de tomografía eléctrica realizadas en la parcela inferior del Templo de Isis (Fig. 8), muestran claramente la geometría del deslizamiento, con alguna estructura muraria basculada a contrapendiente en la parte superior y otras más numerosas basculadas notoriamente hacia el Sur en el pie del deslizamiento, donde se observa una ondulación del nivel del suelo romano muy significativa, causada por sucesivos niveles de despegue en la zona inferior del deslizamiento. La tomografía eléctrica muestra que el deslizamiento romano afecta a los 3-4 m inferiores del antiguo nivel del suelo romano, afectando al nivel de demolición elaborado en el siglo I DC para la reconstrucción de la ciudad, situándose el nivel de despegue basal en el contacto entre este horizonte de demolición y las arcillas del sustrato geológico infrayacente (Fig. 8). Todo el conjunto se encuentra recubierto por el coluvión post-romano (Fig. 8). En base a estos datos la zona deslizada abarcó prácticamente toda la zona de la ciudad situada al Este del Foro y el deslizamiento ligado a la destrucción del acueducto estaría relacionado con el mismo proceso. En total se estima un volumen mínimo de $10.000 \mathrm{~m}^{3}$ para la zona deslizada (Silva y Giner-Robles, 2014). Silva et al. (2009) lo identifican como un deslizamiento cosísmico activado durante los dos terremotos que afectaron a la ciudad, pero fundamentalmente durante el del 260-280 AD. 

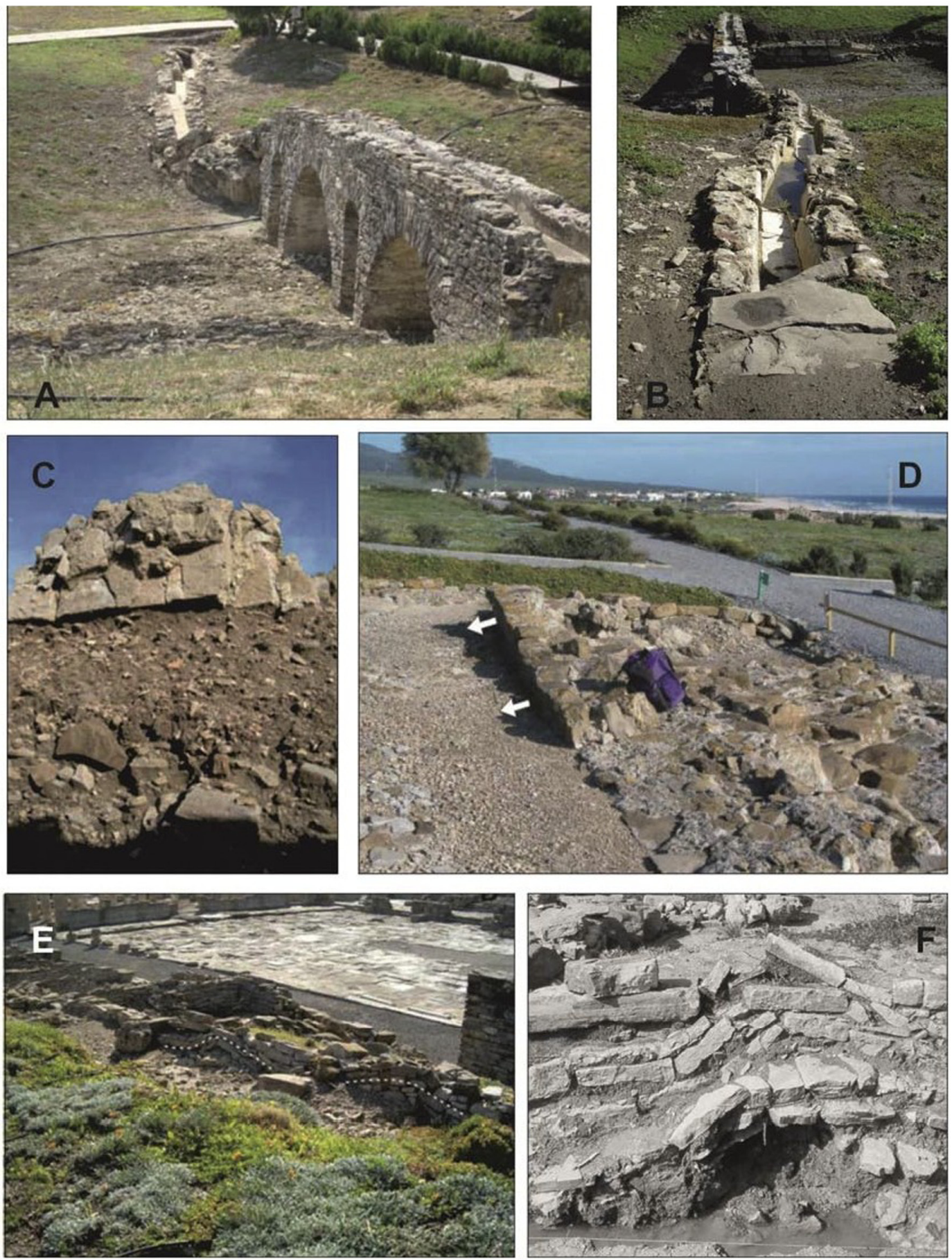

Fig. 7.-EAEs registrados en la zona oriental de Baelo Claudia, Acueducto, Templo de Isis y muros de las tiendas del Foro. A) Vista desde el este del acueducto. Al fondo es se observan la serie de planos paralelos que han producido la rotura y desplazamiento rotacional del acueducto; B) Vista longitudinal de las deformaciones registradas en el acueducto desde la zona de la muralla observándose los desplazamientos decimétricos de los diferentes segmentos afectados; C): Muro colapsado sobre los escombros de la parte occidental del Templo Isis mostrando la estratigrafía de los horizontes de destrucción y posterior ruina al terremoto del 260-290 AD; D) Basculamiento a contrapendiente (ladera arriba) de las estructuras murarías frontales del Templo de Isis, consecuencia del proceso de deslizamiento cosísmico que se describe en el texto (ver situación en Fig. 7); E) Estructuras de plegamiento E-O en los muros N-S de la galería oriental de tiendas del Foro consecuencia del proceso de deslizamiento; F) Detalle de uno de los pliegues de los muros orientales del Foro, observándose las deformaciones que afectan al pavimento y estructuras murarías suprayacentes. 


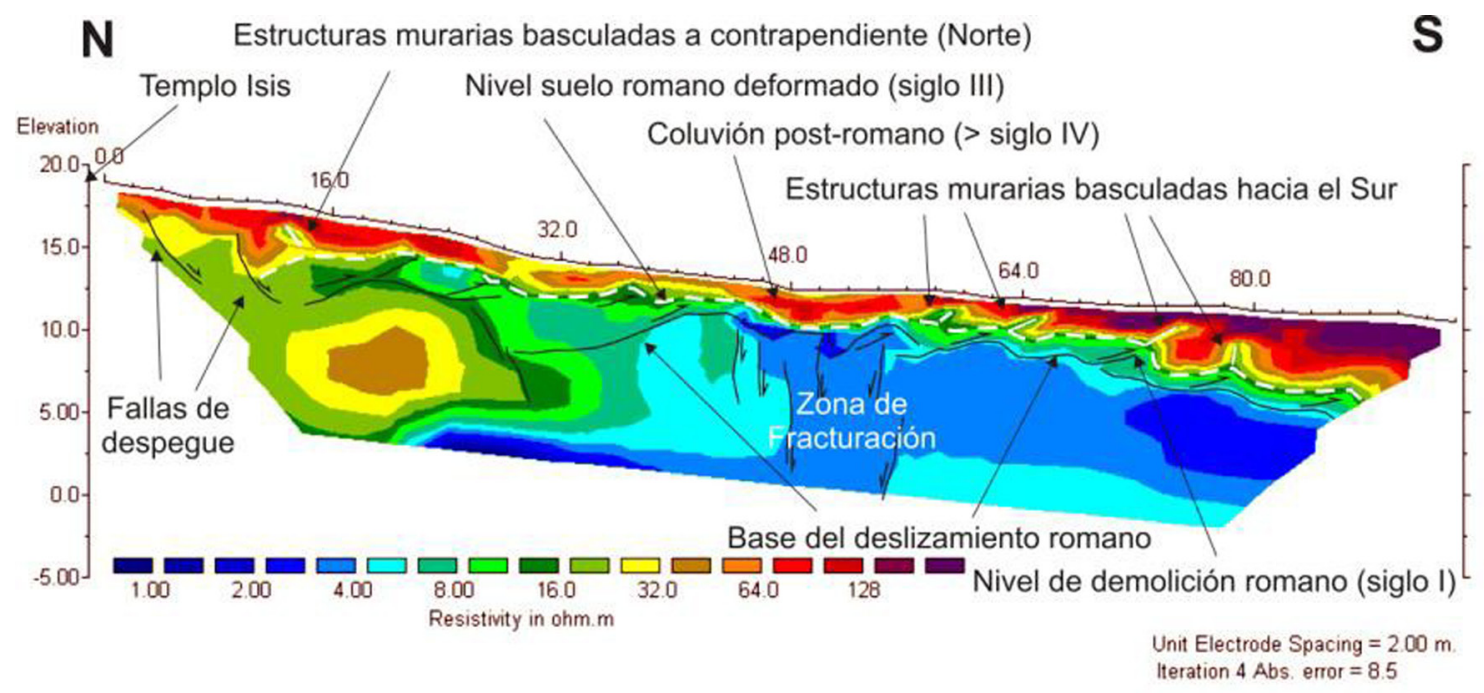

Fig. 8.-Deslizamiento con cabecera en el NE del Templo de Isis (ver Fig. 4). La Tomografía eléctrica se realizó en el sector sin excavar situado inmediatamente ladera abajo del Templo de Isis. En su zona inferior a partir del punto métrico 48.0 se observan claras estructuras murarias basculadas ladera abajo (SSO). En la parte superior se observa el cuerpo principal del deslizamiento que se desarrolla hasta los $5 \mathrm{~m}$ de profundidad y provoca el basculamiento a contrapendiente de algunas estructuras murarías. Todo el conjunto de deformaciones se encuentra enterrado por el coluvión post-romano.

En relación al evento del 40-60 AD, las habitaciones interiores del Templo de Isis muestran una significativa anomalía cronológica. En estas habitaciones aparecen pilares y pequeñas columnas colapsadas, también orientadas principalmente hacia el SO. Dataciones $\mathrm{C}^{14}$ de los materiales en los cuales reposan los elementos colapsados del Templo de Isis $(1900 \pm 30$ BP a 2020 \pm 25 BP; Grützner et al., 2012) se solapan con las de su construcción (siglo I DC) y sugieren una destrucción parcial del Templo durante su construcción (Silva y Giner-Robles, 2014) y su consiguiente remodelación para proseguir con su edificación. Otras dataciones (1725 \pm 30 BP; Grützner et al., 2012) en los rellenos superiores de los colapsos encajarían a grandes rasgos con la fecha del segundo terremoto.

\section{Foro y Basílica}

La zona del Foro y de la Basílica fue reconstruida a finales del siglo primero y comienzos del II DC, con posterioridad a la ocurrencia del primer terremoto (mediados del siglo I AD), aunque la galería oriental de tiendas parece ser uno de los pocos vestigios conservados de la primera ciudad romana en el interior de la ciudad (Sillères, 1997). En la zona del Foro las deformaciones están concentradas en el pavimento de la plaza y en las tiendas de la zona oriental de este conjunto monumental (Fig. 4).
El pavimento enlosado de la plaza del Foro está afectado por numerosas estructuras de deformación, fundamentalmente: plegamientos (anticlinales y sinclinales), estructuras en pop-up e impactos de caída de bloques, siendo los últimos muy importantes en la zona sur del Foro adyacente a la Basílica (Fig. 9). Los pliegues son las estructuras más desarrolladas en esta zona, y sus ejes presentan una orientación media según ONO-ESE (Fig. 9), y si bien esta orientación está condicionada por el enlosado regular que conforma el pavimento de la plaza (Silva et al., 2005; 2009), la dirección de máxima deformación deducida es coherente con las deducidas en otras zonas del yacimiento (Giner-Robles et al., 2011). Otra de las estructuras visibles en el enlosado de la plaza son las estructuras en pop-up (Fig. 9). Estas estructuras se producen como consecuencia de la rigidez de las losas del pavimento del enlosado frente a la deformación producida por el terremoto. En principio se forman los pliegues, pero cuando la deformación aumenta, la falta de espacio y la rigidez de las losas producen la imbricación de las mismas formando popups. Este tipo de estructuras, al presentar mayor grado de libertad de movimientos permite establecer como mayor exactitud la dirección de máxima deformación, en este caso según NE-SO (Giner-Robles et al., 2011). En conjunto todo el sistema de plegamientos que se observa en el Foro está fuertemente condicionado por el proceso de deslizamiento que afectó al Templo de 

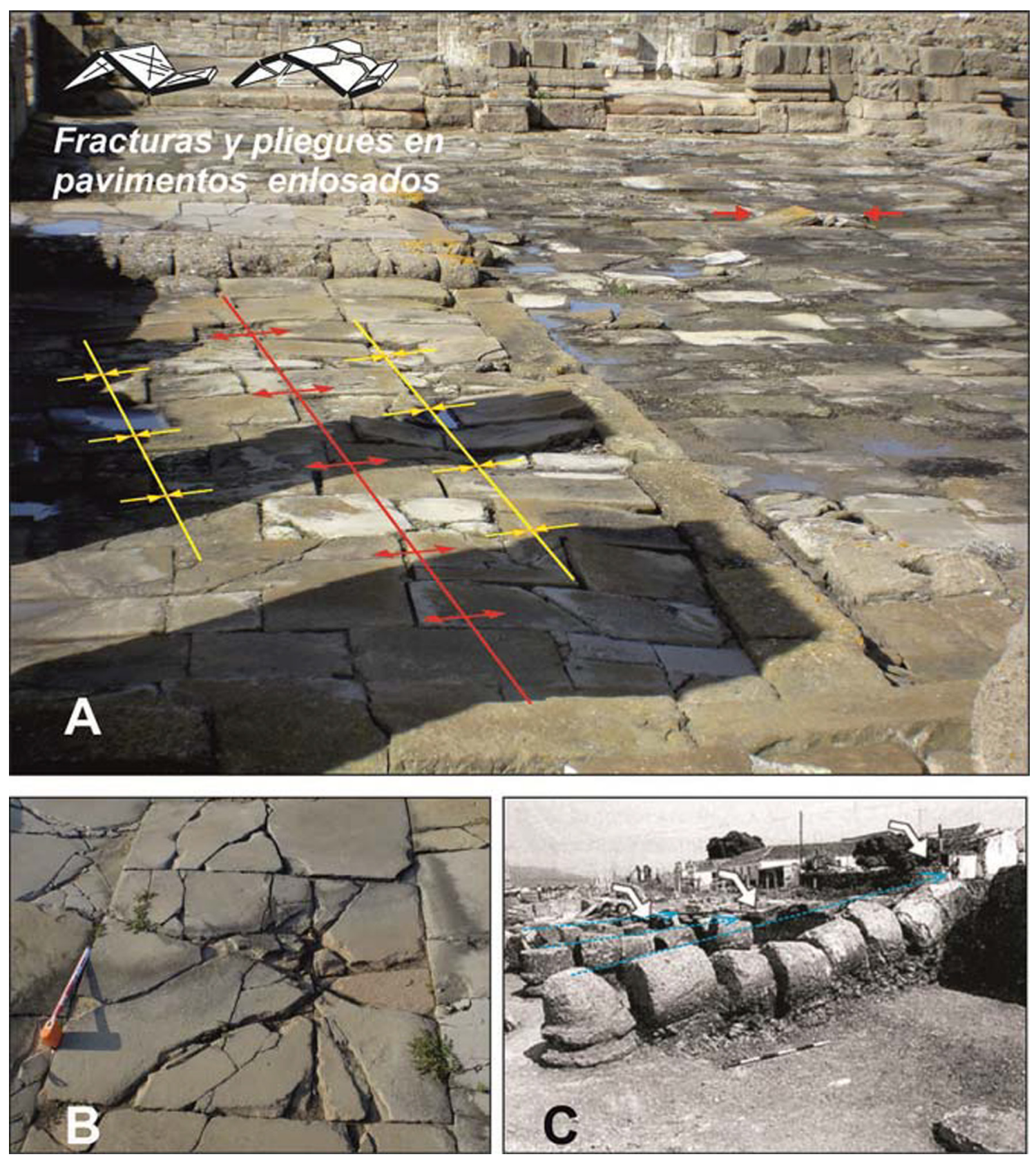

Fig. 9.-Estructuras de deformación en la zona de la plaza del Foro y Basílica. A) Estructuras de plegamiento en la zona de acceso a la Basílica desde el Foro dando lugar a series de anticlinales y sinclinales en el pavimento. Al fondo se observa estructuras en pop-up en el enlosado del Foro; B) Ejemplo de estructuras de impacto por caídas de bloques en el pavimento de la plaza del Foro adyacente a la Basílica; C) Fotografía anterior a la reconstrucción de las columnas de la basílica, en el que se observa el colapso de las columnas hacia el SSO en estilo dominó (modificado de Sillières, 1997).

Isis y al conjunto de la zona oriental de la ciudad (Figs. 8 y 4). En la figura 4 se observa como los plegamientos mejor definidos y desarrollados se encuentran en su zona Sur adyacente a la Basílica y constituirían el frente lobulado del pie del deslizamiento (Fig. 9). Así pues, el deslizamiento al menos se extendió hasta el límite meridional del Foro adyacente a la Basílica, donde procesos de flujo o licuefacción en el pie del deslizamiento pudieron también participar en las importantes deformaciones que se observan en este lugar (Silva et al., 2005). Las catas arqueológicas realizadas en el extremo SE del Foro identifican estructuras 
de deformación sinsedimentarias (pseudo-convolutas) que fueron inicialmente interpretadas como procesos de solifluxión por Menanteau et al. (1983) acorde a las características vérticas - expansivas y pobres propiedades geotécnicas del nivel de demolición y el sustrato arcilloso de la zona.

En esta zona sur del Foro, se observan marcas de impacto por caídas de bloques, desde los pórticos de la Basílica hacia el Norte. Los más importantes se registran en la zona de la puerta de acceso de la Basílica desde el Foro (Fig. 9). En otras zonas de la ciudad (Decumanus maximus) se observan multitud de marcas de impacto por caídas orientadas de los capiteles de las columnas hacía el SSO, congruentes con una llegada de las ondas sísmicas desde esa dirección y con las direcciones de deformación horizontal del terreno preferentes obtenidas para el conjunto del yacimiento (Giner-Robles et al., 2011). En el caso del Foro, la caída orientada de bloques hacia el Norte sería como consecuencia del proceso de deslizamiento cosísmico que definiría una dirección de deformación máxima del terreno NE-SO pero con sentido hacia el SO.

Otra zona que muestra importantes deformaciones en el Foro es la galería de tiendas de su zona oriental (Fig. 4). En esta zona las estructuras murarias $\mathrm{N}-\mathrm{S}$ muestran importantes deformaciones de plegamiento E-O y una importante morfología longitudinal de combamientos en zig-zag de amplio radio, ambos consecuencia del deslizamiento (Fig. 8). Congruentemente a la dirección del proceso de ladera, los muros E-O que separan las distintas tiendas muestran direcciones de basculamiento y colapso hacia el Sur (Fig. 4). La figura 6 ilustra los plegamientos de los muros N-S, así como la significativa ondulación del antiguo pavimento romano, del cual se muestra un detalle del comportamiento plástico del sustrato y pavimento romano (plegamiento) y frágil de las estructuras murarias suprayacentes, en la que el deslizamiento diferencial de los bloques (fracturas intra-bloques) acomoda la deformación.

\section{Mercado (Macellum)}

El mercado de la ciudad (Macellum) también fue construido, como a mayor parte de los edificios de la zona monumental de la ciudad, a finales del siglo I AD, estando ya terminado en el $80 \mathrm{AD}$. En este edificio se observan numerosas estructuras de deformación, tanto en pavimentos como en los diferentes muros que lo conforman. En los muros se observan numerosos bloques de columnas desplazados hacia el SO, orientación coincidente con la de otras estructuras similares en otras zonas del yacimiento (Fig. 10). No obstante las estructuras más llamativas son las numerosas roturas de las esquinas de los bloques que conforman los muros interiores del mercado, que en su totalidad también se orienta hacia el SO (Fig. 10). Estas roturas son debidas al movimiento oscilatorio inducido por las ondas sísmicas, que produce el golpeo de los bloques forzando la rotura de sus esquinas y son un buen efecto indicador del origen sísmico de las deformaciones (Marco, 2008), y de la dirección y sentido del movimiento del terreno durante la sacudida sísmica (Giner-Robles et al., 2011).

\section{Decumanus maximus}

Al sur de la basílica se encuentra la calle principal de este asentamiento: el Decumanus Maximus, orientada aproximadamente E-O. Esta vía de la ciudad esta pavimentada con grandes losas de geometría irregular, las cuales permiten reconocer un buen número de EAEs ligados a la deformación de la zona pavimentada (Fig. 11). Como ya se apuntaba en los primeros estudios arqueosismológicos (Silva et al., 2005; 2009), la geometría irregular del enlosado permite el registro de direcciones de deformación más fidedignas que las que se obtienen en el enlosado del Foro. El enlosado rectangular E-O /N-S del Foro condiciona las direcciones de plegamiento, además en su mayor parte generadas por el proceso de deslizamiento cosísmico. De esta forma las estructuras de plegamiento (sinclinales y anticlinales) del Decumanus se orientan preferentemente en dirección NO-SE indicando una dirección máxima de deformación NE-SO (Fig. 11). Los pliegues se encuentran extendidos a lo largo de todo el Decumanus, y la mayoría de ellos presentan orientaciones similares a las definidas en el mercado y en la zona sur de la Foro y en la plaza de la basílica. Asociadas a estos plegamientos aparecen zonas con subsidencias muy marcadas hacia el SO que escalonan su trazado hacia la Puerta de Gades, situada al Oeste. No obstante, también se registran estructuras plegadas y subsidencias condicionadas por la presencia de estructuras subterráneas (Giner-Robles et al., 2011), en este caso es evidente en tres zonas del Decumanus bajo 


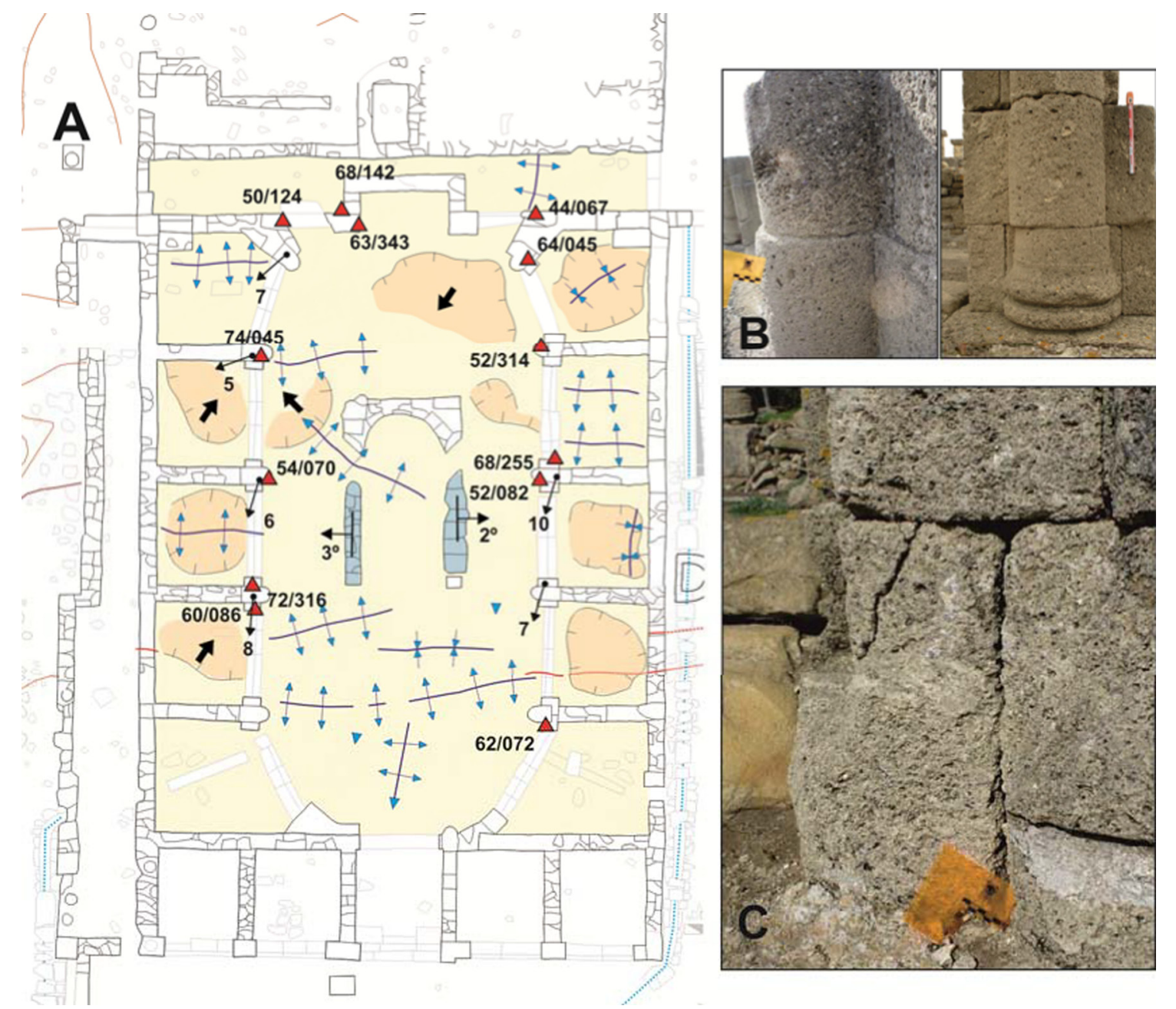

Fig. 10.-Estructuras de deformación en la zona del Macellum (mercado) asociadas con el evento sísmico del 260 -290 AD. A) Cartografía e inventario de EAEs en la zona del Macellum (ver leyenda en Figura 4); B) Desplazamiento inercial de sillares (Bloques desplazados) en las columnas que establecen la separación de las diferentes tiendas del mercado; C) Ejemplo de algunas de las roturas de esquinas de bloques que se pueden observar en las columnas de separación de las tiendas del mercado.

las cuales existen canales de drenaje de la ciudad hacia la costa (Fig. 11).

Entre otros EAEs, los impactos entre las esquinas de las losas y marcas de impacto por caídas de bloques son muy significativos. Los impactos entre losas produce la rotura de sus esquinas de contacto, que en la mayoría de los casos se produce en las esquinas o contactos NE o SO de cada losa individual. Este EAE, al igual que la rotura de esquinas de sillares que se registran en el cercano Macellum, define el sentido de la deformación inducida por el movimiento de las ondas sísmica, marcando una dirección de llegada desde el SO. También se observan numerosos impactos de caídas de bloques, fundamentalmente entre la plaza de la Basílica y el pórtico de la zona de acceso al mercado, a lo largo del lado Norte del Decumanus (Fig. 11). En la mayor parte de los casos se observan caídas orientadas de columnas (en su mayoría) y sillares en dirección SSO. Por el contrario en lado Sur del mismo no se observan tales deformaciones.

\section{Teatro}

El teatro constituye el principal resto arqueológico de la zona NO del sector excavado de la ciudad. Al igual que el resto de los edificios públicos el teatro constituye una de las obras más importantes que acompañaron la reedificación de la ciudad durante la segunda mitad del siglo I DC. Esta importante 


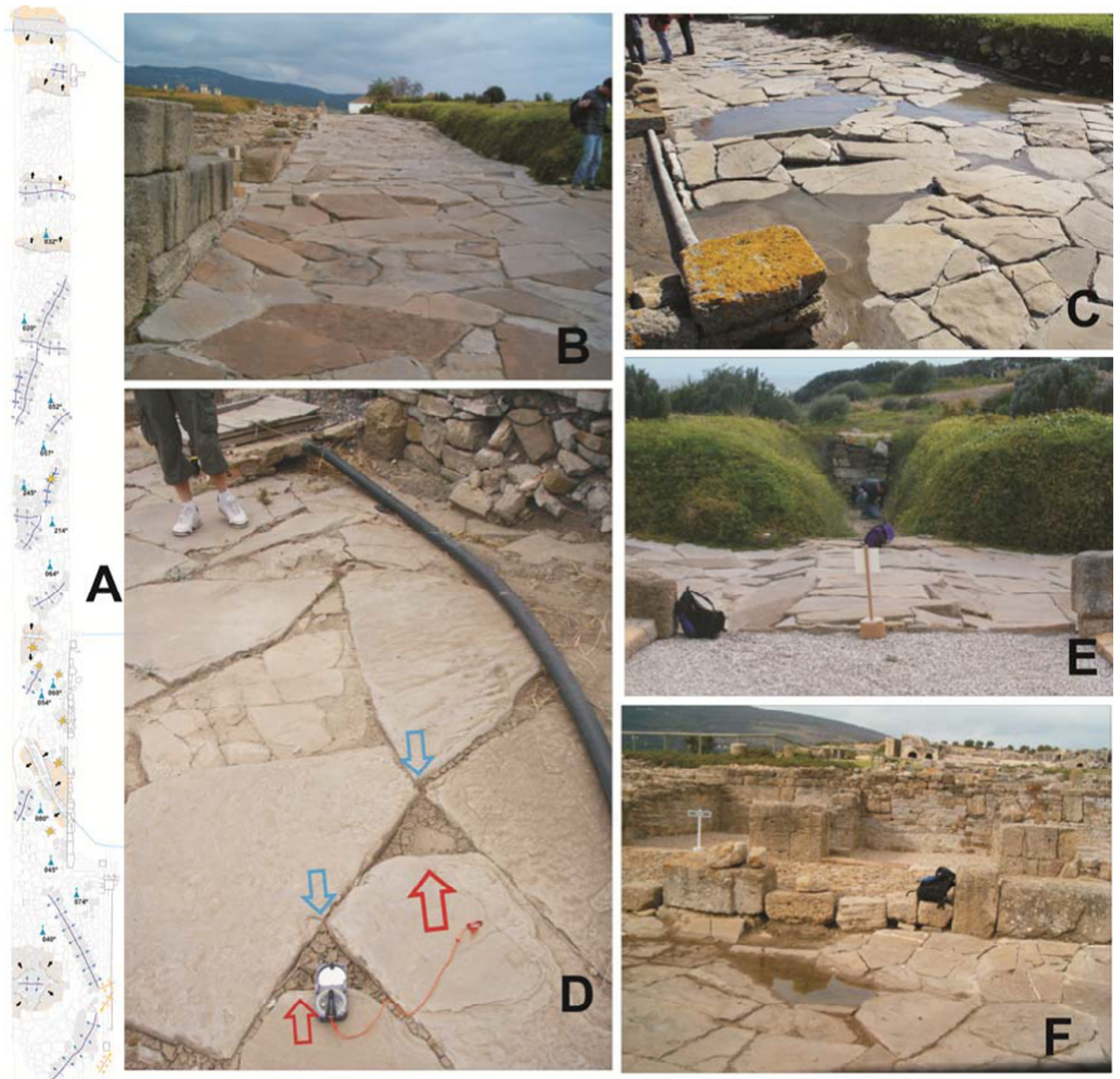

Fig. 11.-Estructuras de deformación registradas en el Decumanus maximus. A) Plano longitudinal del inventario cartográfico de EAEs que se registra en este sector; B y C) vistas generales de las deformaciones, plegamientos, escalonamientos y estructuras pop-ups desarrolladas en el Decumanus; D) Estructuras de impactos entre losas por el movimiento de las ondas sísmicas por el sustrato; E) Plegamiento aparente en el Decumanus como consecuencia de la existencia de estructuras de drenaje (canales) inferiores; F) Estructura de impacto y hundimiento como consecuencia de caída de bloques sobre la zona norte del Decumanus adyacente al Macellum.

edificación muestra dos fases constructivas bien diferenciadas, la primera entre el $10-20 \mathrm{AD}$ y la segunda entre el 70-80 AD (Fincker y Sillières, 2006), lo que constituye una anomalía arqueológica relevante, ya que las obras de su construcción estuvieron paradas unas cinco décadas. Según los autores citados, en el 10-20 AD se interrumpe el proyecto principal y en su reanudación, en el 70-80 AD se modifica el proyecto, se cambia la piedra constructiva de los elementos de mampostería y sillería mayor (piedra caliza marrón por piedra caliza gris) y se construyen las estructuras de apoyo exteriores (contrafuertes; Fig. 12D). La datación de su reconstrucción viene dada por los rellenos de la cávea principal del teatro que se restaura e incluye fragmentos de sillares anteriores de piedra caliza marrón (Fincker y Sillières, 2006).

Las deformaciones que se observan en la actualidad en el Teatro corresponden en su mayoría al evento del 260-280 AD, pero es evidente que se modificó el proyecto principal (incluyendo los refuerzos a la estructura) y se restauraron partes del mismo. Aunque los autores anteriormente citados 

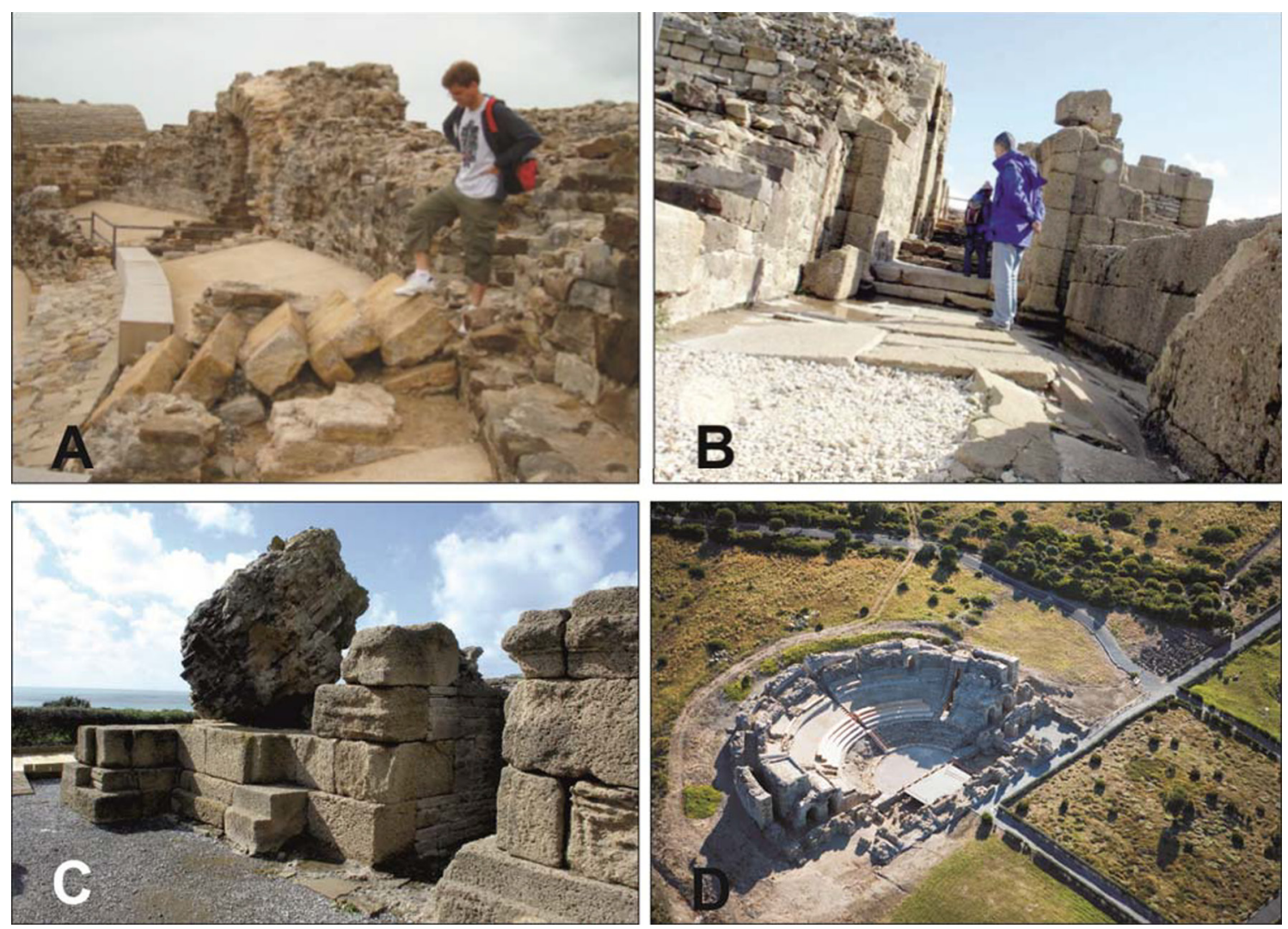

Fig. 12.-Estructuras de deformación y anomalías registradas en el Teatro. A) Escalones colapsados en dominó en dirección SSO en el graderío superior del teatro; B) Plegamiento en el enlosado de uno de los laterales del teatro con orientación similar a las observadas en otras zonas pavimentadas del yacimiento (Foro, Decumanus, Macellum, etc...); C) En la zona baja del teatro es posible observar colapsos de grandes bloques de materiales de la parte superior del mismo, probable consecuencia del proceso de ruina posterior; D) Vista aérea del Teatro en el que se observan algunas de las estructuras de contrafuertes en su perímetro exterior añadidas durante el 70-80 AD, después de la ocurrencia del terremoto del 40-60 AD.

no relacionan estos aspectos con el terremoto 40-60 $\mathrm{AD}$, es evidente que la reanudación de las obras (70-80 AD) y la inclusión de refuerzos externos (Fig. 12D) pueden relacionarse con el primer evento que afectó a la ciudad en el siglo I DC.

$\mathrm{Su}$ sector norte (graderío) se encuentra directamente cimentado sobre el sustrato arcilloso eoceno, pero su sector sur (escenario, cavea y portada) se desarrolla sobre una terraza explanada artificialmente con escombros (2-3 m) sobre depósitos de gravas y arenas de una terraza marina $(1,2 \mathrm{~m})$ que se desarrolla sobre el sustrato arcilloso a $+9 \mathrm{~m}$ (Silva et al., 2005). Esta construcción muestra numerosas estructuras de deformación, aunque el origen sísmico de muchas de ellas no se pueda determinar debido al continuo uso que ha tenido en épocas posteriores a su construcción (reutilización como viviendas por paleocristianos, construcción de una torre de vigilancia por parte de los musulmanes, o como cantera en épocas posteriores).

No obstante, existen estructuras que pueden ser asignadas a la ocurrencia de un sismo (Sillières et al., 1997; Silva et al., 2009). Se puede observar en la parte alta del teatro una escalera colapsada in situ (Fig. 12A). También son visibles otras estructuras muy similares a las observadas en el Foro y en el Decumanus Maximus, como son los plegamientos en los pavimentos enlosados (Fig. 12B). Otros efectos como la caída de grandes bloques (Fig. 12C) que seguramente se encuentran relacionados con el proceso de ruina posterior al segundo terremoto que afectó a la ciudad en el 260-290 AD, aunque su orientación de caída, hacia el SO, es congruente con las orientaciones de los EAEs inventariados en el resto de la ciudad. El teatro no fue destruido en su totalidad por el primer terremoto (40-60 AD), 
aunque con daños graves toda la zona del graderío (Norte) fue reutilizada posteriormente, pero la zona de su cavea y portada principal (Sur) quedó gravemente dañada y hubo que reconstruirse durante el 70-80 AD (Fincker y Sillières, 2006). Por otro lado, la cimentación sobre distintos materiales, fundamentalmente escombros (Talud artificial en el Surportada y cavea) y el sustrato arcilloso (Norte - zona de graderío) pudo tener una incidencia importante en la distribución de los daños inventariados, que se relacionan en su mayoría con el segundo terremoto que afectó a la ciudad a finales del siglo III DC.

\section{Necrópolis Oriental}

La necrópolis oriental de la ciudad se encuentra a la salida oriental de la ciudad al Sur de la Via Carteia, prolongación extramuros del Decumanus maximus (Fig. 2). La necrópolis presenta una significativa anomalía arqueológica difícil de explicar dentro del mundo funerario romano (Prados Martínez y García Jiménez, 2009; Prados Martínez, 2011). Según estos autores, el segundo nivel de tumbas de la necrópolis, fechado en época Claudia ( $<68 \mathrm{AD})$, presenta una importante anomalía funeraria, que recientemente ha sido preliminarmente ligada al terremoto del 40-60 AD (Silva y Giner-Robles, 2014).

En este segundo nivel de enterramientos se encuentran un conjunto de varias decenas de tumbas al Sur de la Vía de Carteia, en las que coexisten tumbas de mayor y menor riqueza con un patrón desordenado (mezclado) y donde se concentra la aparición de los muñecos de Bonsor o "cipos". Todas estas tumbas se encuentran orientadas hacia el mar (hacia el Sur), y no hacia la vía principal de Carteia (hacia el Norte) como en el resto de ciudades romanas. Según Prados Martínez (2011) está anomalía solo se observa en la "Isola Sacra" de la necrópolis de Ostia, no teniendo parangón en el resto del mundo romano, siendo además el carácter desordenado de los enterramientos (mayor y menor riqueza) prácticamente exclusivo de Baelo Claudia. Por lo demás, los muñecos o "cipos" existentes en todas estas tumbas muestran un gesto de "susto" o de "llanto", que no se registra en otras partes del mundo romano de esa época como literalmente describe Prados Martínez (2011). Según este autor la cota a la que se registran estos enterramientos indican que es coetánea a la reconstrucción de las murallas de la ciudad y a la construcción del Decumanus maximus de la población, situándonos en la segunda mitad del siglo I DC.

Aunque Prados Martínez (2011) interpreta estas tumbas, y muñecos asociados, a una tradición regional de raíces púnicas o norte-africanas, parece claro que decenas de ricos y pobres fueron enterrados de forma desordenada, mirando hacia el mar, y con elementos votivos con cara de "susto" o "llanto" (muñecos) durante este periodo de la historia de la ciudad. Aunque no se tiene ningún dato arqueológico que permita suponer que todos los enterramientos son coetáneos, la participación de algún tipo de catástrofe como el terremoto que afectó a la ciudad en el 40-60 AD puede explicar la anomalía arqueológica que representa el patrón desordenado y mezclado de tumbas de ricos y pobres, inusual en el mundo funerario romano (Silva y Giner-Robles, 2014). Por otro lado estos autores indican, que las anomalías relacionadas con la orientación de las tumbas y elementos votivos mirando hacia el mar, y no hacia la Vía Carteia, como ocurre el resto de niveles de enterramiento de la necrópolis y en el mundo romano en general, podría interpretarse con la intervención de un evento tipo tsunami coetáneo al terremoto que asoló a la ciudad durante la segunda mitad del siglo I DC, por otro lado coherente con el carácter probablemente marino de las fuentes sísmicas (Fig. 1) que pudieron ocasionar los terremotos que afectaron a esta ciudad (Silva et al., 2009; Grützner et al., 2012).

Como se ha comentado en la introducción, existen datos sobre niveles litorales energéticos, ligados a la ocurrencia de un evento tipo tsunami cuyas fechas coinciden con las del terremoto del 40-60 AD. En un arroyo próximo a Baelo Claudia $(500 \mathrm{~m}$ al Este de su muralla; Fig. 2) Alonso-Villalobos et al. (2003) identifican un nivel de arenas y gravas litorales energético fechado por $\mathrm{C}^{14}$ entre el cal. $200 \mathrm{AC}$ y 125 AD. Arteaga y González Martín (2004) identifican otro nivel energético de arenas marinas relacionado con la destrucción de una zona de talleres de alfarería en la antigua ciudad romana de Carteía, localizada en la Bahía de Algeciras a unos $33 \mathrm{~km}$ hacia el Este de Baelo Claudia, que fechan arqueológicamente en la segunda mitad del siglo I DC. Por tanto, no se puede descartar la intervención de un evento marino en la destrucción de la ciudad (Silva y Giner-Robles, 2014). En cualquier caso, las cotas a 
que se encuentran estos niveles energéticos indican que de tratarse de un tsunami, este sería de pequeñas dimensiones (1-2 $\mathrm{m}$ de altura) y con un poder de penetración restringido, probablemente inferior a los 300-500 m tierra adentro (Silva et al., en prensa). Las reconstrucciones paleogeográficas realizadas por estos autores (véase Fig. 2) indican que el posible tsunami no penetraría mucho más allá del actual Decumanus maximus, pero afectaría a la zona más baja de la ciudad donde se encuentran las fábricas de salazones y las antiguas instalaciones portuarias. Sobra comentar que ambas zonas de la ciudad, situadas en su litoral, serían las de mayor actividad comercial y humana en la época y en el caso de la llegada de un pequeño tsunami ocasionaría decenas de muertes.

\section{Discusión y Conclusiones}

Los efectos arqueosismológicos (EAEs) documentados en Baelo Claudia son numerosos y variados, sirviendo como modelo para el desarrollo de metodologías en el análisis de orientaciones de daños (Giner-Robles et al., 2011) que posteriormente se han aplicado a otros yacimientos arqueológicos o a elementos del patrimonio histórico artístico en diversas partes del mundo. Los EAEs documentados en Baelo Claudia casi representan la totalidad de los EAEs recogidos en la clasificación de Rodríguez-Pascua et al. (2011) y en su mayor parte corresponden al registro del terremoto que provocó la destrucción de la ciudad en el 260-290 AD y quedan plasmados en la cartografía de daños de la figura 4 (Giner-Robles et al., 2013).

Los EAEs más importantes que documentan este evento sísmico son los siguientes: (a) plegamiento de pavimentos de argamasa (Macellum y Curia); (b) fracturas, plegamientos y pop-ups en enlosados regulares (Foro); (c) fracturas, plegamientos y pop-ups en enlosados irregulares (Decumanus); (d) compactación diferencial del terreno (Basílica, Decumanus). Así mismo existen numerosos ejemplos de efectos secundarios sobre la fábrica de las construcciones, tales como: (a) impactos entre enlosados (shock breakouts; Decumanus); (b) Contrafuertes desplazados y girados (Cisterna, Teatro); (c) Muros basculados (Muralla y estructuras murarias en la ciudad); (d) Muros plegados (tiendas de la parte oriental del Foro); (e) fracturas penetrativas en bloques de sillería (Muralla, Macellum y edificios anexos a la Basílica); (f) Fracturas conjugadas (Muralla, edificios anexos a la Basílica); (g) Caída orientada de columnas (Basílica y Templo de Isis); (h) Claves de arco desplazadas (Muralla, Basílica, Termas); (i) Escalones y líneas de bordillo plegadas (Plaza de la Basílica, Teatro); (j) Esquinas de sillares fracturadas (Dipping broken corners, Macellum, Basílica); (k) Marcas de impacto (Decumanus y Foro) y Sillares desplazados (Macellum, Teatro y templos). Todas estas estructuras se encuentran generadas por la deformación permanente $(a-d)$ o transitoria del sustrato $(\mathrm{e}-\mathrm{k})$ consecuencia del movimiento del terreno al paso de las ondas sísmicas (Giner-Robles et al., 2011; Rodríguez-Pascua et al., 2011).

El análisis de las orientaciones de daños en todas estas estructuras indican una orientación homogénea NE-SO, definiendo una dirección de deformación horizontal máxima del terreno $\mathrm{N} 35^{\circ}-\mathrm{N} 40^{\circ} \mathrm{E}$ para la totalidad del conjunto arqueológico. El hecho de que estas orientaciones sean consistentes dentro de una categoría de EAEs particular (plegamientos del pavimento, caídas orientadas, esquinas de sillares fracturadas, etc.) y para el conjunto de ellos en el antiguo entorno urbano (Fig. 4) permite proponer que las deformaciones orientadas poseen un origen sísmico común relacionado con la dirección del movimiento del terreno promovida por la propagación de ondas sísmicas. Algunos de los EAEs permiten no solo obtener la dirección, sino también la orientación o sentido del movimiento, como es el caso de sillares desplazados, colapso orientado de columnas, impactos de inter-losados y roturas en las esquinas de los sillares (Fig. 3), que indican un sentido consistente desde el SO, sugiriendo una fuente sísmica cercana localizada en las inmediaciones de la Bahía de Bolonia (Silva et al., 2005; 2009). Otros autores, proponen también la ocurrencia de terremotos en la segunda mitad del siglo III AD que afectarían a las ciudades romanas de Corduba y Munigua (Villanueva del Rio y Minas, Sevilla), solapándose temporalmente con el segundo de los terremotos que afectó a Baelo Claudia (Monterroso, 2011; Morín de Pablos et al., 2014). Lejos de poder hablar de un gran terremoto (tipo Lisboa) que afectará a numerosas poblaciones del cuadrante SO de Andalucía, habría que pensar en la ocurrencia de una crisis 
sísmica tardoromana con la ocurrencia de terremotos moderados pero destructivos en campo cercano (M 5.5-6.0), como parecen indicar terremotos tardoromanos más lejanos identificados en Ilunum (Minateda, Albacete; Rodríguez-Pascua et al., 2011) y Complutum (Alcalá de Henares,Madrid; Rodríguez-Pascua et al., 2016).

Como se ha mencionado, la historia de Baelo Claudia se ha "construido" progresivamente en base al análisis e interpretación de los sucesivos hallazgos arqueológicos (Sillières, 1997), ya que salvo la breve referencia del Geógrafo Estrabón no existe historia escrita referente a la ciudad. Menanteau et al. (1983) son los primeros autores que proponen la participación de un evento sísmico en la destrucción y posterior abandono de la ciudad. Posteriormente Sillières $(1995 ; 1997)$ indica expresamente que la ciudad fue afectada por dos eventos sísmicos, el primero durante el siglo I DC y el segundo a finales del siglo III DC. El análisis de daños correspondientes al segundo terremoto indica claramente la intervención de un terremoto en la destrucción de la ciudad (Silva et al., 2009; GinerRobles et al., 2011; 2013). El terremoto del siglo I DC se encuentra menos documentado en las deformaciones analizadas, no obstante los daños analizados en las murallas indican una similar orientación de la deformación (SO) aunque estadísticamente estos datos no son representativos. En cualquier caso, existen numerosas anomalías arqueológicas que apoyan la ocurrencia de este primer terremoto en el 40-60 AD, como la destrucción de dos terceras partes de la muralla y los trabajos de reparación posterior (Sillières, 1997), las anomalías cronológicas de elementos colapsados en el Templo de Isis (Grützner et al., 2012), el desarrollo de un extenso y potente nivel de demolición en la zona baja de la ciudad (Silva et al., 2005), las anomalías de los rellenos y reconstrucción de la cavea del teatro (Fincker y Sillières, 2006) y las anomalías funerarias en el segundo nivel de enterramientos de la necrópolis oriental de la ciudad (Prados Martínez, 2011). En cualquier caso, la intervención de dos terremotos es la causa más probable que pueda explicar los dos periodos de destrucción de la ciudad, apoyada en sólidos datos cuantitativos de carácter arqueométrico extraídos del análisis arqueosismológico del conjunto del yacimiento.
Aunque no existe ningún dato concluyente al respecto, puede interpretarse que la ciudad adquirió el rango de Ciudad Romana (Claudia) y que durante la ampliación y monumentalización de la misma (40-60 AD) ocurrió un terremoto que afectaría en diverso grado a la parte baja de la ciudad y monumentos en construcción (p.ej. Teatro, Templo de Isis). Este evento, que bien pudo no ser excesivamente importante (intensidad $\geq$ VIII EMS), facilitaría la demolición de buena parte de la ciudad y la implantación de una nueva planta urbana acorde con su nuevo status. El evento del 260-290 AD fue más importante que el primero, pudiendo alcanzar intensidad $\geq$ IX EMS y la decadencia del imperio romano evitó su nueva reconstrucción.

Como se ha indicado en la parte introductoria, no se descarta que un evento de tipo tsunami de baja magnitud afectara a la zona durante el evento del siglo I DC, tal y como sugieren las anomalías funerarias documentadas en la necrópolis oriental de la ciudad y el registro de niveles enérgéticos marinos de época romana en las cercanías de la ciudad (Alonso Villalobos et al., 2003). Datos arqueológicos y geocronológicos recientes (Röth et al., 2015) indican que un evento tipo tsunami también participó en la destrucción de la ciudad ocurrida durante el terremoto de finales del siglo III. Estos autores documentan la existencia de microfauna marina en los niveles más arenosos situados inmediatamente encima del Decumanus maximus, así como un depósito de backwash rellenando parcialmente las termas marítimas, situadas extramuros en la zona más litoral (Fig. 2). Ambos depósitos son interpretados como tsunamitas (Röth et al., 2015) y refuerzan la hipótesis de la naturaleza marina de la fuente sismogenética propuesta en trabajos previos (Fig. 2). Así tras casi quince años de investigación arqueosismológica en Baelo Claudia (2001-2015), se puede afirmar que dos terremotos, acompañados de tsunamis de escaso poder de penetración se encuentran registrados en el Conjunto Arqueológico Romano de Baelo Claudia. Ambos terremotos han sido incluidos en el nuevo catálogo de efectos Geológicos de los Terremotos editado por el IGME (Silva y Rodríguez-Pascua, 2014) con la única finalidad de que sean recogidos en futuros análisis de peligrosidad sísmica de la zona y mejorar las estimaciones al respecto. 


\section{AGRADECIMIENTOS}

Este trabajo ha sido financiado por sucesivos proyectos de investigación en la zona desde el año 2001 y en la actualidad por los Proyectos de Investigación CGL2015-67169-P (USAL: QTECTSPAIN), CGL2012-37281-C02.01 (USAL: QTECTBÉTICA) y CGL2012-33430 (MNCN, CSIC). Es una aportación del grupo de Trabajo de Tectónica Activa, Paleosismología y Arqueosismología (QTEC-AEQUA). Los autores están agradecidos a las facilidades y apoyo en la investigación que nos han brindado a lo largo de todos estos años los responsables del Conjunto Arqueológico Romano de Baelo Claudia (Junta de Andalucía). Los autores agradecen los comentarios de Antonio Monterroso y José M. Azañón que han contribuido a mejorar el presente trabajo.

\section{Referencias}

Alonso-Villalobos, F.J.; Gracia-Prieto, F.J.; Ménanteau, L.; Ojeda, R.; Benavente, J. \& Martínez, J.A. (2003). Paléogeographie de l'anse de Bolonia (Tarifa, Espagne) à l'époque romaine. In: Fouache, E. (Ed.). The Mediterranean World Environment and History. Elsevier, Amsterdam, 407-417.

Ambraseys, E. (2006). Earthquakes and archaeology. Journal of Archaeological Science, 33 (7): 1008-1016. http://dx.doi.org/10.1016/j.jas.2005.11.006

Arteaga, C. \& González Martín, J.A. (2004). Presencia de materiales marinos y dunares sobre un alfar romano en la Bahía de Algeciras (Cádiz, España). In: Benito, G. (Ed.). Actas de la VIII Reunión Nacional de Geomorfología, SEG, Toledo. Vol. 1, 393-400.

Borja, F.; Martínez, A., \& Troya, A. (1993). El proceso histórico de destrucción de la Ciudad Romana de Baelo Claudia (SW Cádiz): caracterización geotécnica y análisis de formaciones superficiales. Arqueología Espacial, 16-17: 297-308.

Espinar Moreno, M. (1994). Los estudios de sismicidad histórica en Andalucía: los terremotos históricos de la provincia de Almería. In: Posadas, A.M. (Coord.). El estudio de los terremotos en Almería. Instituto de Estudios Almerienses, Almería, 115-180.

Galbis, R.J. (1932). Catálogo sísmico de la zona comprendida entre los meridianos $50^{\circ} \mathrm{E}$ y $20^{\circ} \mathrm{W}$ de Greenwich y los paralelos $45^{\circ}$ y $25^{\circ} \mathrm{N}$. Tomo I. Dirección General del Instituto Geográfico. Catastral y de Estadística, Madrid, $567 \mathrm{pp}$.

Giner-Robles, J.L.; Silva, P.G.; Pérez-López, R.; Rodríguez-Pascua, M.A.; Bardají, T.; Garduño-Monroy, V.H. \& Lario, J. (2011). Evaluación del daño sísmico en edificios históricos y yacimientos arqueológicos: aplicación al estudio del riesgo sísmico. Proyecto EDASI. Serie Investigación. Fundación MAPFRE, Madrid, 96 pp.

Giner-Robles, J.L.; Martín-González, F.; Pérez-López, R.; Rodríguez-Pascua, M.A. \& Silva, P.G. (2012).
Oriented fall structures (EAE's): a review in instrumental earthquakes. In: Proceedings $3^{\text {rd }}$ INQUA-IGCP 567 International Workshop on Earthquake Archaeology and Palaeoseismology, Morelia, México, 51-54.

Giner-Robles, J.L.; Silva, P.G.; Rodríguez-Pascua, M.A.; Pérez-López, R. \& Bardají, T. (2013). Mapa de efectos arqueológicos de terremotos (EAEs) en la ciudad romana de Baelo Claudia (Cádiz, España). LibroGuía Excursiones, VIII Reunión Cuaternario Ibérico (Anexo), AEQUA, Sevilla.

Grützner; C.; Reicherter, K.; Hübscher, C. \& Silva, P.G. (2012). Active faulting and neotectonics in the Baelo Claudia area, Campo de Gibraltar (Southern Spain). Tectonophysics, 554-557: 127-142. http://dx.doi. org/10.1016/j.tecto.2012.05.025

Ferrater, M.; Silva, P.G.; Ortuño, M.; Rodríguez-Pascua, M.A. \& Masana, E. (2015). Archaeoseismologic analysis of a Late Bronze Age site on the Alhama de Murcia Fault: Tira del Lienzo (Murcia, SE Spain). Geoarchaeology, 30 (2): 151-164. http://dx.doi.org/ $10.1002 /$ gea. 21505

Fincker, M. \& Sillières, P. (2006). Le Théâtre De Baelo Claudia: Particularités Architecturales et Chronologie. In: Ventura, A.V. \& Márquez C. (Eds.). Jornadas sobre Teatros romanos en Hispania, Córdoba, 2002, 81-98.

Lario, J.; Luque, L.; Law, C.; Goy, J.L.; Spencer, C.; Cabero, A.; Bardaji, T.; Borja, F.; Dabrio, C.; Civis, J.; González-Delgado, J.A.; Borja, C. \& Alonso-Azcárate, J. (2010). Tsunami vs. Storm surge deposits: a review of the sedimentological and geomorphological records of extreme wave events (EWE) during the Holocene in the gulf of Cadiz, Spain. Zeitschrift für Geomorphologie, 54 (supl. 3): 301-316. http:// dx.doi.org/10.1127/0372-8854/2010/0054S3-0029

Marco, S. (2008). Recognition of earthquake-related damage in archaeological sites: examples from the Dead Sea fault zone. Tectonophysics, 453 (1-4): 148156. http://dx.doi.org/10.1016/j.tecto.2007.04.011

Martínez Solares, J.M. \& Mezcua, J. (2002) Catálogo sísmico de la Península Ibérica (880 a. C.-1900). Monografías IGN, 8, Ministerio de Fomento, Madrid, $256 \mathrm{pp}$.

Menanteau, L.; Vanney, J.R. \& Zazo, C. (1983). Belo II: Belo et son environment (Détroit de Gibraltar), Etude physique d'un site antique. Publications de la Casa de Velázquez, Serie Archeologie, 4. Broccard, París. 83 pp.

Monterroso Checa, A. (2011). Córdoba romana: historiografía abierta sobre arquitectura y urbanismo. Antiqvitas, 23: 149-175.

Morín de Pablos, J.; Silva, P.G.; Rodríguez-Pascua, M.A. \& Sánchez Ramos, I.M. (2014). Evidencias arqueosismo-lógicas en la Colonia Patricia Romana de Corduba (Valle del Guadalquivir, España). In: Álvarez Gómez, J.A. et al. (Eds.). Una aproximación 
multidisciplinar al estudio de las fallas activas, los terremotos y el riesgo sísmico: IBERFAULT II, Lorca. IGME, 159-162.

Prados Martínez, F. (2011). La necrópolis oriental de Baelo Claudia (Tarifa, Cádiz) en el contexto de la religiosidad púnico-mauritana: una lectura a partir de las últimas actuaciones arqueológicas. Zephyrus, 68: 191-210.

Prados Martínez, F. \& García Jiménez, I. (2009). Aproximación al paisaje funerario de la necrópolis oriental de Baelo Claudia (Tarifa, Cádiz): una lectura social. Aljaranda, 72, 4-12.

Rodríguez-Pascua, M.A.; Pérez-López, R.; Silva, P.G.; Giner-Robles, J.L.; Garduño-Monroy, V.H. \& Reicherter, K. (2011). A Comprehensive Classification of Earthquake Archaeological Effects (EAE) for Archaeoseismology. Quaternary International, 242 (1): 20-30. http://dx.doi.org/10.1016/j.quaint.2011. 04.044

Rodríguez-Pascua, M.A.; Abad Casal, L.; Pérez-López, R.; Gamo Parra, B.; Silva, P.G.; Garduño-Monroy, V.H.; Giner-Robles, J.L.; Perucha, M.A.; Israde-Acántara, I.; Bischoff, J. \& Calvo, J.P. (2013). Roman, Visigothic and Islamic evidence of earthquakes recorded in the archaeological site of "El Tolomo de Minateda" (Prebetic Zone, SE Spain). Cuaternario y Geomorfología, 27 (3-4): 83-90. http://hdl.handle. net/10045/35323

Rodríguez-Pascua, M.A.; Heras, C.; Bastida, A.B.; Giner-Robles, J.L.; Silva, P.G.; Perucha, M.A.; Roquero, E.; Carrasco, P.; Pérez-López, R.; Lario, J. \& Bardají, T. (2014). Evidencias Arqueosísmológicas de la destrucción de Complutum en el siglo IV AD (Cuenca del Tajo, España). In: Álvarez Gómez, J.A. et al. (Eds.). Una aproximación multidisciplinar al estudio de las fallas activas, los terremotos y el riesgo sísmico: IBERFAULT II, Lorca. IGME, 147-150.

Rodríguez-Pascua, M.A.; Silva, P.G.; Perucha, M.A.; Giner-Robles, J.L.; Heras, C.; Bastida, A.B.; Carrasco, P.; Roquero, E.; Lario, J.; Bardají, T.; Pérez-López, R. \& Elez, J. (2016). Seismically induced liquefaction structures in La Magdalena archaeological site, the 4th century AD Roman Complutum (Madrid, Spain). Sedimentary Geology, in press. http://dx.doi.org/10.1016/j.sedgeo.2016.01.025

Röth, J.; Mathes-Scmidt, M.; García Jiménez, I.; Rojas Pichardo, F.J.; Grürtzner, C.; Silva, P.G. \& Reicherter, K. (2015). The Baelo Claudia tsunami hypothesis: results from a multi-method sediment analysis of late-Roman deposits (Gibraltar Strait, Southern Spain). In: Blumetti, A.M., et al. (Eds.). 6th International Inqua Meeting on Paleoseismology, Active Tectonics and Archaeoseismology, 19-24 April 2015, Pescina, Fucino Basin, Italy. Miscallenea INGV 27, 418-422.

Sillières, P. (1995). Le Capitole de Baelo Claudia: Un cas d'incohérence de datations archéologique et stylistique et un exemple de solution. Annas, 7-8: 285-298.

Sillières, P. (1997). Baelo Claudia: Una ciudad Romana de la Bética. Casa de Velázquez, Madrid, 237 pp.

Sintubin, M.; Stewart, I. \& Niemi, T. (2010). Ancient earthquakes. Geological Society of America Profesional Papers, 471. Geological Society of America, Boulder, Colorado, 279 pp. http://dx.doi. org/10.1130/978-0-8137-2471-3

Silva, P.G.; Borja, F.; Zazo, C.; Goy, J.L.; Bardají, T.; De Luque, L.; Lario J. \& Dabrio, C.J. (2005). Archaeoseismic record at the ancient Roman City of Baelo Claudia (Cádiz, south Spain). Tectonophysics, 408 (1-4): 129-146. http://dx.doi.org/10.1016/j. tecto.2005.05.031

Silva, P.G.; Reicherter, K.; Grützner, Ch.; Bardají, T.; Lario, J.; Goy, J.L.; Zazo, C. \& Becker-Heidmann, P. (2009). Surface and subsurface palaeoseismic records at the ancient Roman city of Baelo Claudia and the Bolonia Bay area, Cádiz (south Spain). Geological Society of London, Special Publication, 316: 93-121. http://dx.doi.org/10.1144/SP316.6

Silva, P.G. \& Rodríguez-Pascua, M.A. (Eds.) (2014). Catálogo de Efectos Geológicos de los terremotos en España. Serie Riesgos Geológicos / Geotecnia IGME, 4. Instituto Geológico y Minero de España, Madrid, 358 pp.

Silva P.G. \& Giner-Robles J.L. (2014). Bolonia (Cádiz), 40-60 AD. In: Silva P.G. \& Rodríguez-Pascua M.A. (Eds.). Catálogo de Efectos Geológicos de los terremotos en España. Serie Riesgos Geológicos / Geotécnia IGME, 4. Instituto Geológico y Minero de España, Madrid, 87-92.

Stiros, S. (2001). The AD 365 Crete earthquake and possible seismic clustering during the fourth to sixth centuries $\mathrm{AD}$ in the Eastern Mediterranean: a review of historical and archaeological data. Journal of Structural Geology, 23 (2-3): 545-562. http://dx.doi. org/10.1016/S0191-8141(00)00118-8

Stiros, S. \& Jones, R.E. (1996). Archaeoseismology. Occasional Papers of the Fitch Laboratory, 7. British School at Athens, $268 \mathrm{pp}$.

Udías, A. \& Muñoz, D. (1983). Estudios de sismicidad histórica en España. In: Seminario sobre sismicidad y riesgo sísmico en el área Ibero-Mogrebi. IGN, Córdoba, 35-40. 